\title{
Interpretation of stress measurements made around closed-ended displacement piles in sand
}

\author{
R. J. JARDINE*, B. T. ZHU†, P. FORAY $\ddagger$ and Z. X. YANG $\S$
}

\begin{abstract}
An interpretation is given of instrumented calibration chamber experiments involving comprehensive measurements of the stresses developed on and around closed-ended model displacement piles installed in pressurised silica sand. Conclusions are drawn regarding the mechanisms and stress regimes that apply during and after penetration, and how these compare with cavity expansion treatments and other analyses. The experimental arrangements and measurement details are described fully in a companion paper.
\end{abstract}

KEYWORDS: model test; piles; sands; stress analysis; stress path

\section{INTRODUCTION}

Considerable uncertainty exists over the stress conditions developed around displacement piles, particularly when considering sands in which vertical tip stresses may exceed those acting on the shaft by orders of magnitude. Experiments are required to give key insights and test potential conjectures, assumptions and hypotheses regarding the stress regimes applying during and after installation. Establishing these stress conditions is critical to improving the understanding and modelling of features such as non-linear loaddisplacement behaviour, group installation effects, or base and shaft capacity variations with time.

Jardine et al. (2013) report measurements made as $36 \mathrm{~mm}$ diameter steel instrumented piles and cone penetration test (CPT) probes were jacked into pressurised, air-pluviated Fontainebleau NE34 sand in the heavily instrumented INPG calibration chamber illustrated in Fig. 1. The fine sand $\left(D_{50}=0.21 \mathrm{~mm}\right)$ was placed at an average initial void ratio $e_{0}=0.62$ and relative density $D_{\mathrm{r}}=72 \%$; its mechanical properties are described by Yang et al. (2010), Jardine et al. (2013) and Altuhafi \& Jardine (2011), who consider particle breakage, one-dimensional compression, triaxial and interface shear behaviour under a wide range of pressures.

The pile experiments described included two 'pilot' tests made with a CPT probe, and three installations with a stainless steel Mini-Imperial College pile (ICP). A vertical surcharge of $\sim 200 \mathrm{kPa}$ was applied in the first test, CPT1, which was reduced to $\sim 150 \mathrm{kPa}$ for the following installations. As outlined in Fig. 2 and Tables 1-3, continuous measurements were made in the sand mass of local $\sigma_{r}^{\prime}, \sigma_{\theta}^{\prime}$ and $\sigma_{z}^{\prime}$ trends by up to 40 sensors per installation. Shaft interface stresses $\tau_{r z}$ and $\sigma_{r}^{\prime}$ were recorded at three points on the Mini-ICP, and axial loads were measured at four to five levels. Boundary conditions and jacking styles varied slightly between the installations. Jardine et al. (2013) describe how

Manuscript received 22 September 2011; revised manuscript accepted 12 October 2012. Published online ahead of print 1 February 2013. Discussion on this paper closes on 1 November 2013, for further details see p. ii.

* Department of Civil and Environmental Engineering, Imperial College London, UK.

$\dagger$ NOMA Consulting Pty Ltd, Australia; formerly Imperial College.

$\$$ Laboratoire Sols, Solides, Structures-Risques, Institut Polytechnique de Grenoble, France.

$\S$ Research Center of Coastal and Urban Geotechnical Engineering, Department of Civil Engineering, Zhejiang University, China; formerly Imperial College. end bearing and $q_{\mathrm{c}}$ profiles were established for each test. They showed that the soil stresses developed during installation correlated directly with the local $q_{\mathrm{c}}$ values; normalisation by $q_{\mathrm{c}}$ reduced the influence of variations in test arrangements. Shaft failure was shown to be governed in all cases by the Coulomb law, with operational $\delta^{\prime}$ values that matched parallel laboratory interface ring-shear tests.

One test involved installation by steady jacking. The pile heads were unloaded fully in the brief 'stationary periods' imposed between jack strokes in all other tests, leading to two-way shaft failure during each cycle that involved both contractant and dilative phases. The number of extreme cycles per installation ranged from $N=1$ (for the steadily jacked pile) to $N=200$ in Mini-ICP2 when a $5 \mathrm{~mm}$ stroke length was imposed. Stroke lengths of $10 \mathrm{~mm}$ were imposed in the three other installations, giving $N=100$. The installation stresses varied greatly between stationary (s) and moving (m) stages of penetration, and were critically dependent on the instruments' locations relative to the pile tips. The sand-mass stresses were insensitive to $N$ and the periods of the installation cycles; however, the pile/soil interface stresses may be more affected by these variables (Jardine et al., 2013).

Field tests suggest that the stresses developed on the shafts of piles driven in sands vary considerably over the weeks and months that follow installation: see for example Chow (1997), Chow et al. (1998), Axelsson (2000) or Jardine et al. (2006). The model piles did not show any strong evidence of time dependence over their installation periods. However, they were jacked relatively slowly, and Rimoy (2012) is investigating whether stronger rate and time effects apply during the installation of dynamically driven piles.

\section{SYNTHESIS OF SOIL STRESS MEASUREMENTS}

This paper presents further synthesis of the large volume of stress measurements made with the sensor arrays illustrated in Figs 1 and 2. It also refers the results to cavity expansion analyses, which have been considered relevant to displacement pile behaviour in sand by, for example, Vesic (1972), Yu \& Houlsby (1991), Salgado et al. (1997) and White et al. (2005).

Following from Jardine et al. (2013), the interpretation assumes that the $\sigma_{z}^{\prime}, \sigma_{r}^{\prime}$ and $\sigma_{\theta}^{\prime}$ stresses (within the region that is unaffected by the chamber's boundary conditions) developed in the sand mass, during and shortly after installation, under any fixed initial free field vertical stress $\sigma_{z 0}^{\prime}$, can 


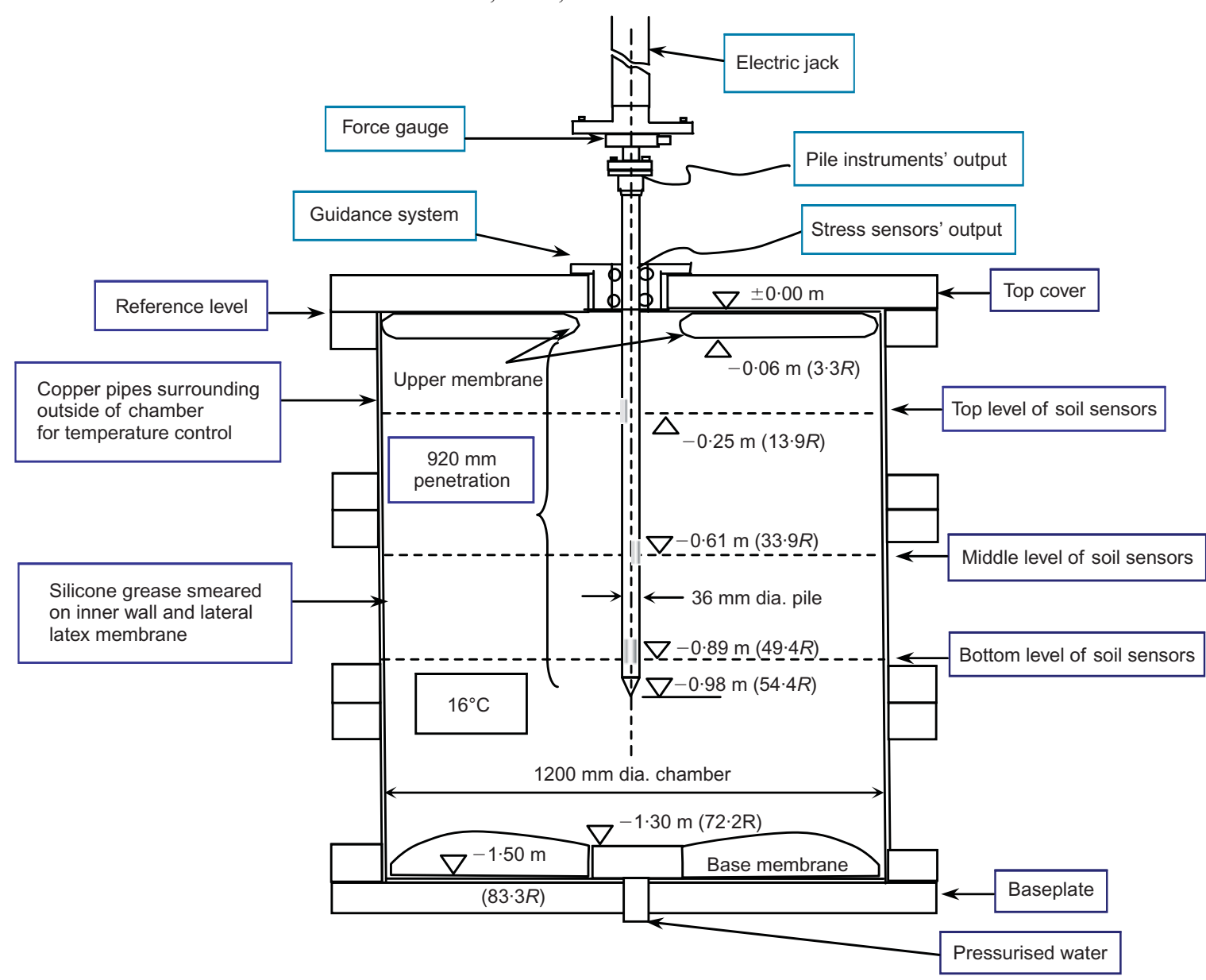

Fig. 1. Schematic diagram of Mini-ICP1 test, showing one example instrument layout. Leading, following and trailing pile sensor clusters positioned at $h / R=6 \cdot 7,21 \cdot 7$ and $41 \cdot 7$ respectively. See Table 1 and Fig. 2 for the configuration of sensors. Base membrane was not only applied in Mini-ICP 2 or Mini-ICP 3 tests

be expressed by two-dimensional, axially symmetric functions as

$$
\frac{\sigma^{\prime}}{q_{\mathrm{c}}}=f\left(\frac{h}{R}, \frac{r}{R}\right)
$$

where $r / R$ is the relative radius from the pile axis, and $h / R$ is the (positive) relative height above or (negative) depth below the pile tip. The treatment implicitly neglects any dependence on the number of jacking cycles, or time effects. As noted by Lehane et al. (1993) and Jardine et al. (2005), an additional (albeit weak) dependence on $\sigma_{z 0}^{\prime}$ may be expected in the field, or in centrifuge tests, where $\sigma_{z 0}^{\prime}$ increases significantly down the length of the pile shaft.

Jardine et al. (2013) discuss the difficulties of measuring stresses within a soil mass accurately. The regime developed around driven or jacked piles is particularly hard to study, because of the extreme stress changes developed. Fig. 3 illustrates the variations with pile tip depth $\left(L_{\mathrm{p}}\right)$ of the minimum and maximum radial stress envelopes established in Mini-ICP1 by three levels of sensors positioned at $r$ / $R=2$. Maxima developed for each instrument as the pile tip passed the level at which it had been set. The plots emphasise the spread of data and the substantial cyclic span between the (moving) stress maxima and (stationary) minima. Jardine et al. (2013) explain why individual measurements are subject to unusually high scatter and possible error, even when close attention is paid to all experimental details.

Independent data from three installations are brought together in Fig. 4, considering sensors positioned at $r / R=2$ and various depths $(z)$ below the sand surface. The pile tip defines the geometrical origin, and $\sigma_{r}^{\prime} / q_{\mathrm{c}}$ traces are plotted against each sensor level's (varying) normalised height $(h /$ $R$ ) above the tip at the time of measurement. Note that $h / R$ is initially negative, and becomes positive when the penetrating tip reaches each sensor's particular level. The 'moving' $\sigma_{r \mathrm{~m}}^{\prime} / q_{\mathrm{c}}$ trends, expressed as means with standard deviations $( \pm \mathrm{SD})$ in brackets, rise as the pile approaches from above to give $0 \cdot 57( \pm 0 \cdot 25) \%$ when $h / R=-10$, build to a maximum of $19 \cdot 7( \pm 3 \cdot 4) \%$ just after the tip has passed (at $h / R=0 \cdot 5$ ), and then decline. So, for example, $\sigma_{r \mathrm{~m}}^{\prime} / q_{\mathrm{c}}$ reduces to $1 \cdot 19( \pm 0 \cdot 24) \%$ at $h / R=15$. The equivalent 'stationary' $\sigma_{r \mathrm{~s}}^{\prime} / q_{\mathrm{c}}$ values were $0 \cdot 65( \pm 0 \cdot 18) \%, 8 \cdot 3( \pm 1 \cdot 6) \%$ and $1 \cdot 22( \pm 0 \cdot 28) \%$ respectively. The coefficients of variation $(\mathrm{COV}=\mathrm{SD} /$ mean $)$ are lower for 'moving' stages than 'stationary', and are lowest for the 'maxima' developed when $h / R=0 \cdot 5$. The radial stress COVs are also lower than those for $\sigma_{\theta}^{\prime}$ or $\sigma_{z}^{\prime}$. Averaging was essential to data interpretation, and Appendix 1 describes how the thousands of individual measurements were

(a) synchronised to eliminate possible positioning errors

(b) averaged to reduce scatter

(c) synthesised to produce normalised stress component contour plots. 


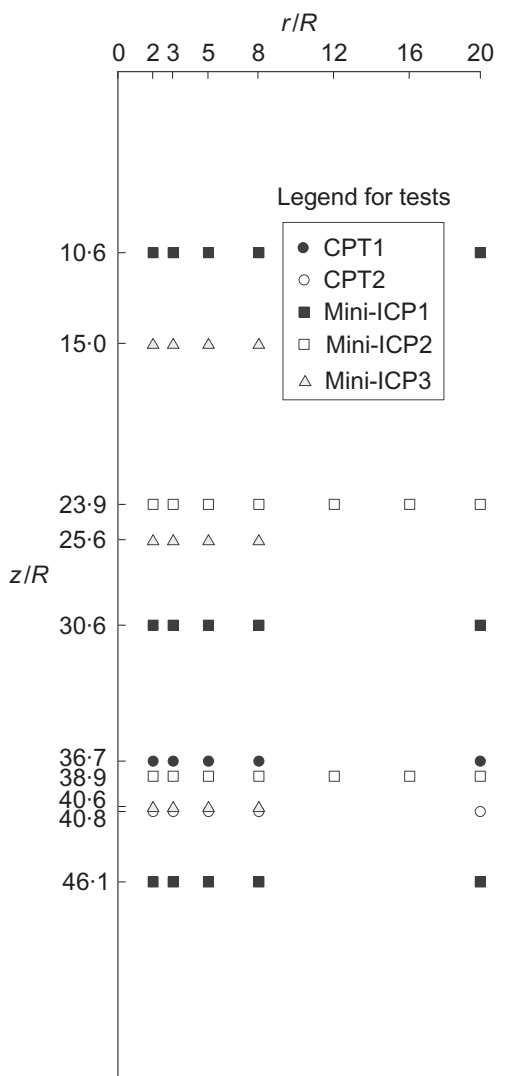

(a)

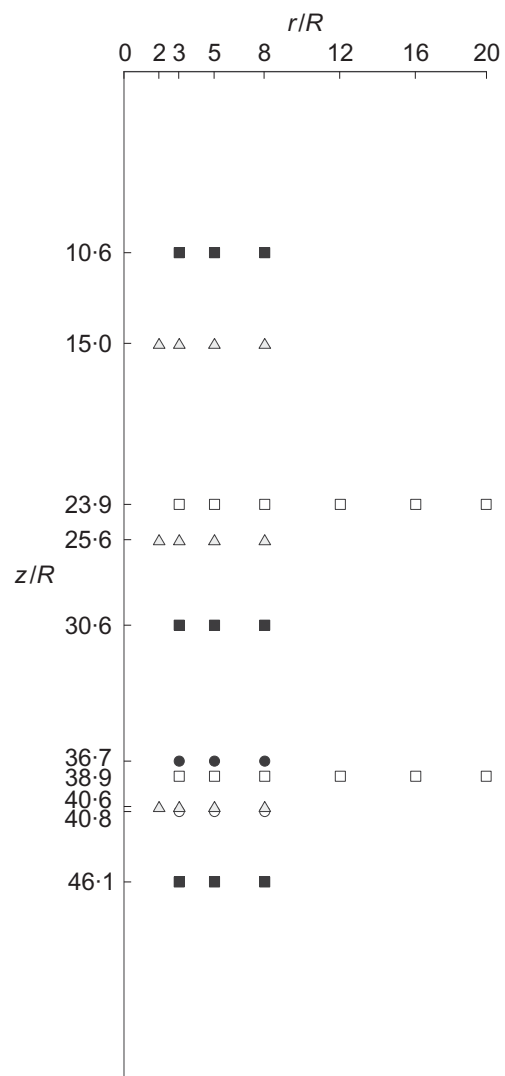

(b)

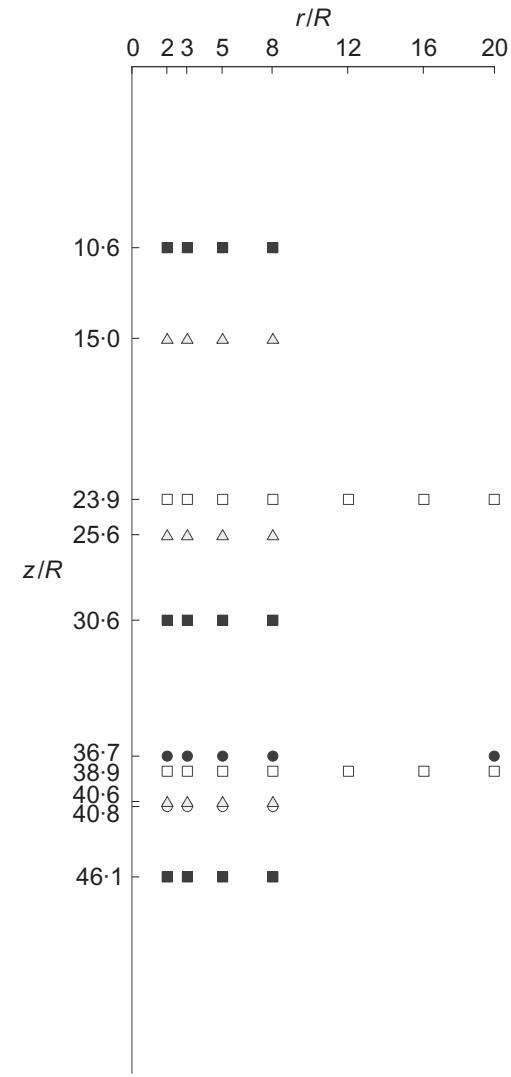

(c)

Fig. 2. Schematic diagram of placement positions of soil stress sensors deployed in tests listed in Table 1. Sensors placed at optimal positions circumferentially, as detailed by Jardine et al. (2009)

Table 1. Summary of soil stress sensor locations for pile tests considered

\begin{tabular}{l|c|c|c|c|c}
\hline Test & $\begin{array}{c}\text { Depth below sand } \\
\text { surface: } \mathrm{mm}\end{array}$ & $\begin{array}{c}z / R \text { value at } \\
\text { sensor level }\end{array}$ & $\begin{array}{c}\text { Radial sensor positions, } \\
r / R\end{array}$ & $\begin{array}{c}\text { Vertical sensor positions, } \\
r / R\end{array}$ & $\begin{array}{c}\text { Circumferential sensor positions, } \\
r / R\end{array}$ \\
\hline CPT1 & 660 & $36 \cdot 7$ & $2\left(\mathrm{~F}^{*}\right), 3,5,8(\mathrm{~F}), 20$ & $3,5,8$ & $2,3(\mathrm{~F}), 5,8$ \\
CPT2 & 735 & $40 \cdot 8$ & $2,3,5,8,20$ & $3,5,8(\mathrm{~F})$ & $2(\mathrm{~F}), 3(\mathrm{~F}), 5(\mathrm{~F}), 8(\mathrm{~F})$ \\
Mini-ICP1 & Top: 190 & $10 \cdot 6$ & $2,3(\mathrm{~F}), 5,8,20$ & $3(\mathrm{~F}), 5,8(\mathrm{~F})$ & $2,3(\mathrm{~F}), 5,8(\mathrm{~F})$ \\
& Middle: 550 & $30 \cdot 6$ & $2,3,5,8,20$ & $3,5,8$ & $2,3(\mathrm{~F}), 5,8(\mathrm{~F})$ \\
& Bottom: 830 & $46 \cdot 1$ & $2,3(\mathrm{~F}), 5,8,20(\mathrm{~F})$ & $3,5(\mathrm{~F}), 8$ & $2(\mathrm{~F}), 5,8(\mathrm{~F})$ \\
Mini-ICP2 & Top: 430 & $23 \cdot 9$ & $2,3,5,8,12,16,20$ & $3,5(\mathrm{~F}), 8(\mathrm{~F}), 12(\mathrm{~F}), 16,20$ & $2(\mathrm{~F}), 3,5,8,12,16,20$ \\
& Bottom: 700 & $38 \cdot 9$ & $2,3,5,8,12,16,20$ & $3,5,8,12,16,20$ & $2,3,5,8,12,16,20$ \\
Mini-ICP3 & Top: 270 & $15 \cdot 0$ & $2(\mathrm{~F}), 3,5,8$ & $2,3(\mathrm{~F}), 5,8$ & $2,3,5,8(\mathrm{~F})$ \\
& Middle: 460 & $25 \cdot 6$ & $2,3,5,8$ & $2,3(\mathrm{~F}), 5(\mathrm{~F}), 8$ & $2(\mathrm{~F}), 3,5,8$ \\
& Bottom: 730 & $40 \cdot 6$ & $2(\mathrm{~F}), 3,5,8(\mathrm{~F})$ & $2(\mathrm{~F}), 3,5(\mathrm{~F}), 8$ & $2(\mathrm{~F}), 3,5,8(\mathrm{~F})$ \\
\hline
\end{tabular}

$* \mathrm{~F}=$ failure, attrition rate $=32 \%$.

Table 2. Summary of total number of soil stress measurements applied in developing average traces for input into contouring

\begin{tabular}{l|c|c|c}
\hline $\begin{array}{l}\text { Soil stress } \\
\text { measurements }\end{array}$ & $\begin{array}{c}\text { Number of raw measurements for end } \\
\text { of push stages }\end{array}$ & $\begin{array}{c}\text { Number of raw measurements for end } \\
\text { of pause stages }\end{array}$ & $\begin{array}{c}\text { Final set entered into } \\
\text { contouring routines }\end{array}$ \\
\hline$\sigma_{r}^{\prime}$ & 4932 & 4932 & $\begin{array}{l}726 \text { (push) } \\
749 \text { (pause) } \\
747 \text { (push) } \\
871 \text { (pause) } \\
\sigma_{\theta}^{\prime}\end{array}$ \\
$\sigma_{z}^{\prime}$ & 3188 & 3188 (push) \\
875 (pause)
\end{tabular}

\section{Radial stress}

Figure 5 presents two normalised radial stress contour maps, one corresponding to 'moving' $\sigma_{r \mathrm{~m}}^{\prime} / q_{\mathrm{c}}$ trends, the other to 'stationary' $\sigma_{r \mathrm{~s}}^{\prime} / q_{\mathrm{c}}$ conditions. They show generally comparable patterns, with intense stress concentrations focused near the tip, at $r / R=0, h / R \approx 0.5$. If the stress amplitude of each jacking cycle is defined as being half the difference between the moving and stationary values, then 
Table 3. Summary of total number of pile stress measurements used in stress distribution interpretation

\begin{tabular}{l|c|c|c}
\hline $\begin{array}{l}\text { Pile stress } \\
\text { measurements }\end{array}$ & $\begin{array}{c}\text { Number of raw measurements for end } \\
\text { of push stages }\end{array}$ & $\begin{array}{c}\text { Number of raw measurements for end } \\
\text { of pause stages }\end{array}$ & $\begin{array}{c}\text { Number of final set entered into } \\
\text { contouring routines }\end{array}$ \\
\hline$\sigma_{r}^{\prime}$ & 870 & 870 & 6 \\
$\tau_{r z}$ & 870 & 870 & 6 \\
\hline
\end{tabular}

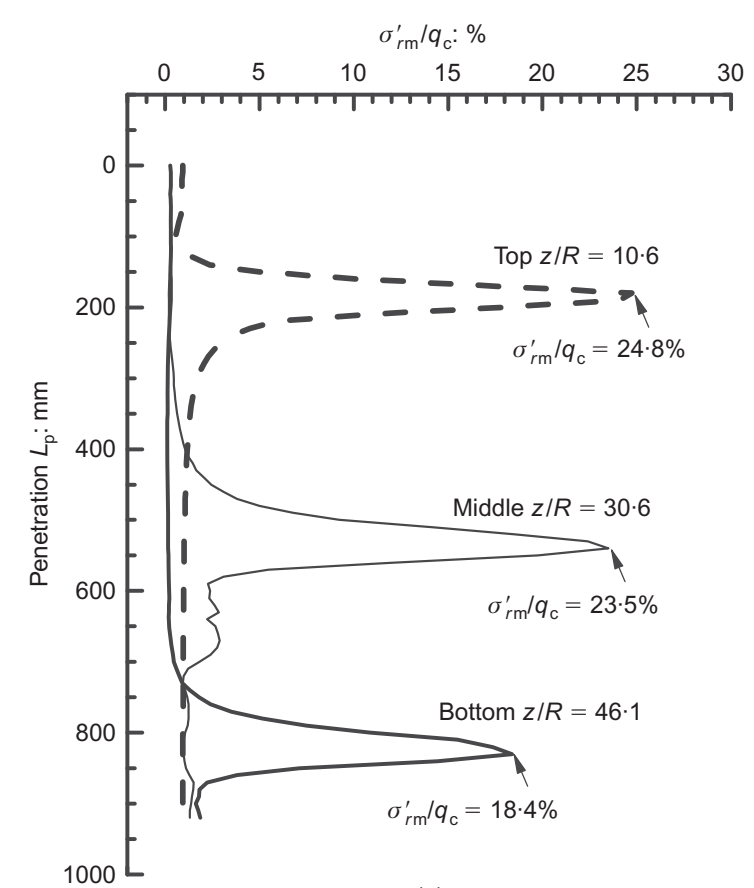

(a)

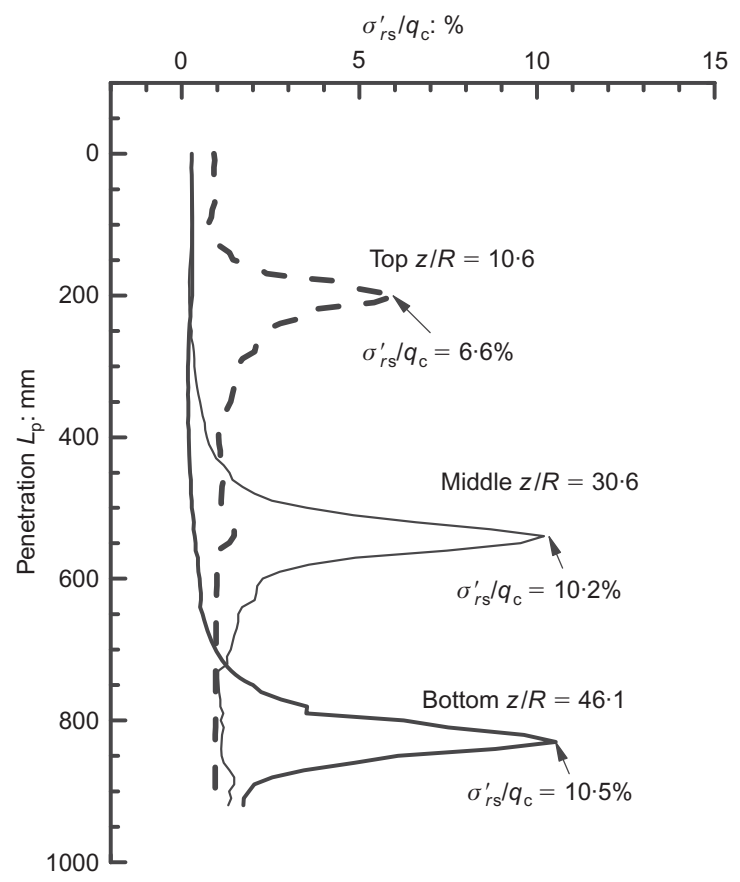

Fig. 3. Normalised radial stresses measured at $r / R=2$, also showing individual maximum values: (a) 'moving' and (b) 'stationary' cases for Mini-ICP1 plotted against penetration depth, $L_{\mathrm{p}}$

the amplitudes amount to $\sim 1 / 3$ of the average $\sigma_{r}^{\prime} / q_{\mathrm{c}}$ developed over each cycle at points within $10 R$ of the tip. The stress gradients $\left(\delta \sigma_{r}^{\prime} / \delta h\right)$ are steeper above the tip than below during penetration; this trend inverts during pauses.
The dashed curves added to Fig. 5 show the loci of the $h / R$ elevations where $\sigma_{r}^{\prime}$ maxima were observed for any given $r / R$. The highest moving radial stresses (observed at $h / R \approx 0 \cdot 5, \quad r / R=2$ during steady penetration) exceeded $0 \cdot 15 q_{\mathrm{c}}$ and were around double the equivalent stationary values. The $\sigma_{r \mathrm{~m}}^{\prime} / q_{\mathrm{c}}$ observations made with all instruments at the 'maximum' $h / R=0.5$ level presented in Fig. 6 show a scattered but consistent pattern. Despite variations between individual test configurations, the overall trend is to confirm equation (1): $\sigma^{\prime} / q_{\mathrm{c}}=f(h / R, r / R)$.

Radial stresses exceeding the measurements may be expected closer to the pile tip. White \& Bolton (2004) and Yang et al. (2010) argue that soils fail in axial compression beneath pile tips during penetration. The average of the $\sigma_{\mathrm{zm}}^{\prime}$ values developed just below the conical tip should match $q_{\mathrm{c}}$; for simplicity, it is assumed that $\sigma_{z \mathrm{~m}}^{\prime} / q_{\mathrm{c}}=1$ uniformly over the cone surface. At the $h / R=0.5$ level, this limit applies at the cone/soil interface, which is positioned at $r / R=$ $1 /(2 \sqrt{ } 3) \approx 0 \cdot 29$. Vertical stresses can be expected to reduce beneath the tip with increasing $r / R$ and depth. The corresponding 'tip zone' radial stress maximum should match $\sigma_{r \mathrm{~m}}^{\prime}=K_{\mathrm{A}} q_{\mathrm{c}}$ during steady penetration. Altuhafi \& Jardine (2011) conducted triaxial experiments on NE34 sand designed to match: (a) the near pile tip regime, with $\sigma_{1}^{\prime} \approx q_{\mathrm{c}} \approx 22 \mathrm{MPa}$, and (b) the paths followed by sand near the axis that is first heavily loaded by the approaching tip, and then both displaced laterally to higher $r / R$ and substantially unloaded as the tip passes. Critical state $\phi_{\mathrm{cs}}^{\prime} \approx 30^{\circ}$ under high-pressure compression, implying $K_{\mathrm{A}}=\tan ^{2}\left(45-\phi_{\mathrm{cs}}^{\prime} / 2\right)=1 / 3$ and $\sigma_{r \mathrm{~m}}^{\prime}=q_{\mathrm{c}} / 3$ near the cone surface. Significantly higher peak triaxial shear strengths $\left(\phi^{\prime} \approx 42^{\circ}\right)$ were developed in drained recompression tests run on specimens that had been unloaded to $150>p^{\prime}>500 \mathrm{kPa}$ after first experiencing high-pressure active failure. This implies that larger $\phi^{\prime}$ values can be realised in an intermediate zone located above the tip, and laterally within $1<r / R<3$, where the sand has experienced high pressures, crushing and radial displacement prior to unloading as the tip passed. The 'cone surface' $\sigma_{r \mathrm{~m}}^{\prime}=q_{\mathrm{c}} / 3$ value is shown as a single point at $r / R=0 \cdot 29$ in Fig. 6 .

Elastic-plastic cavity expansion analyses developed by $\mathrm{Yu}$ \& Houlsby (1991) for sands with constant $\phi^{\prime}$ predict that the principal stresses have a power-law variation with normalised radius $r / R$ within the expanding 'moving' plastic region

$$
\frac{\sigma_{r}^{\prime}}{\sigma_{R}^{\prime}}=\left(\frac{r}{R}\right)^{c}
$$

where $\sigma_{R}^{\prime}$ is the stress at $r / R=1 ; c=m\left(1-K_{\mathrm{P}}\right) / K_{\mathrm{P}}$ and $K_{\mathrm{P}}=\tan ^{2}\left(45+\phi^{\prime} / 2\right) ; m=1$ for cylindrical cavities and $m=2$ for spherical expansion. Plotted logarithmically in Fig. 6, the individual (non-averaged) stress measurements trend to decay with $r / R^{-1 \cdot 23}$ when $r / R>2$. However, gentler gradients are required over the $0.29<r / R<2$ range to connect the measurement trend to the 'tip zone' $\sigma_{r \mathrm{~m}}^{\prime}=q_{\mathrm{c}} / 3$. The minimum and maximum $\phi^{\prime}$ laboratory values $\left(30^{\circ}\right.$ and $42^{\circ}$ ) give 'spherical case' predictions for $c$ of -1.33 and -1.6 respectively, which exceed the measurement trends indicated in Fig. 6; the 'cylindrical case' predictions $(-0.66$ 


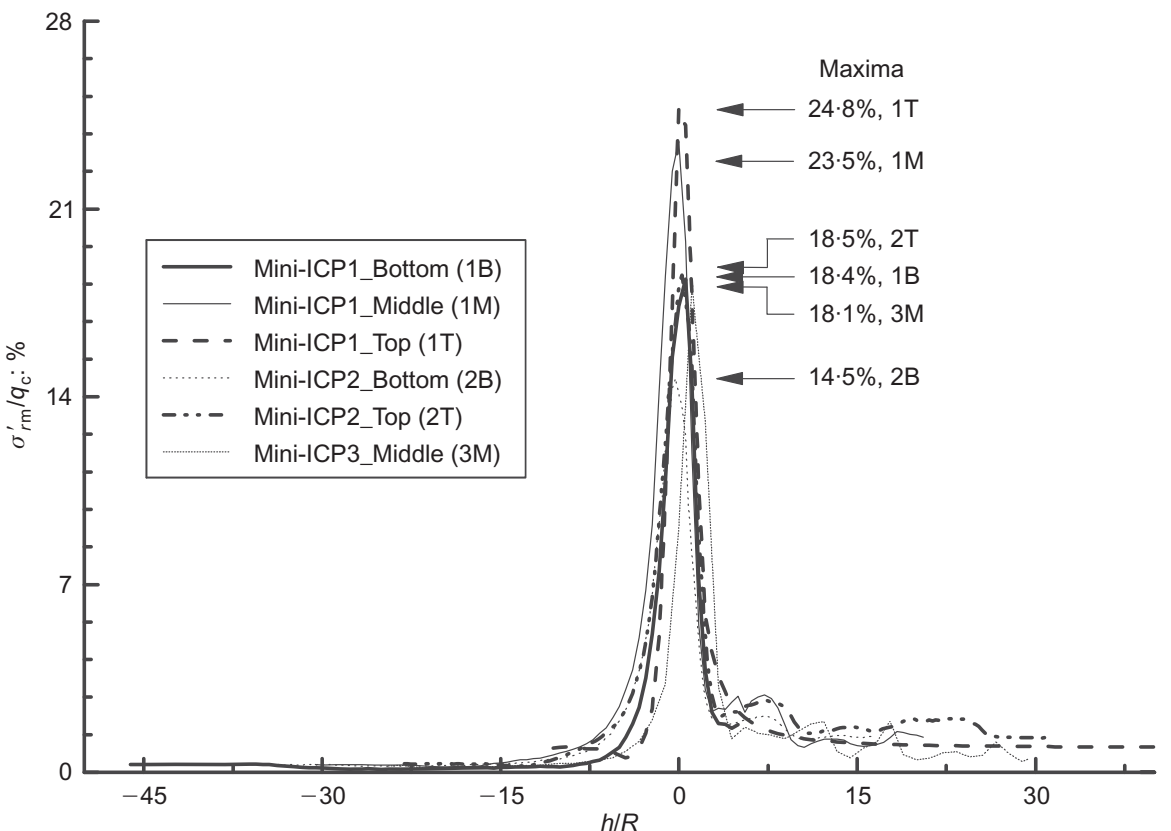

(a)

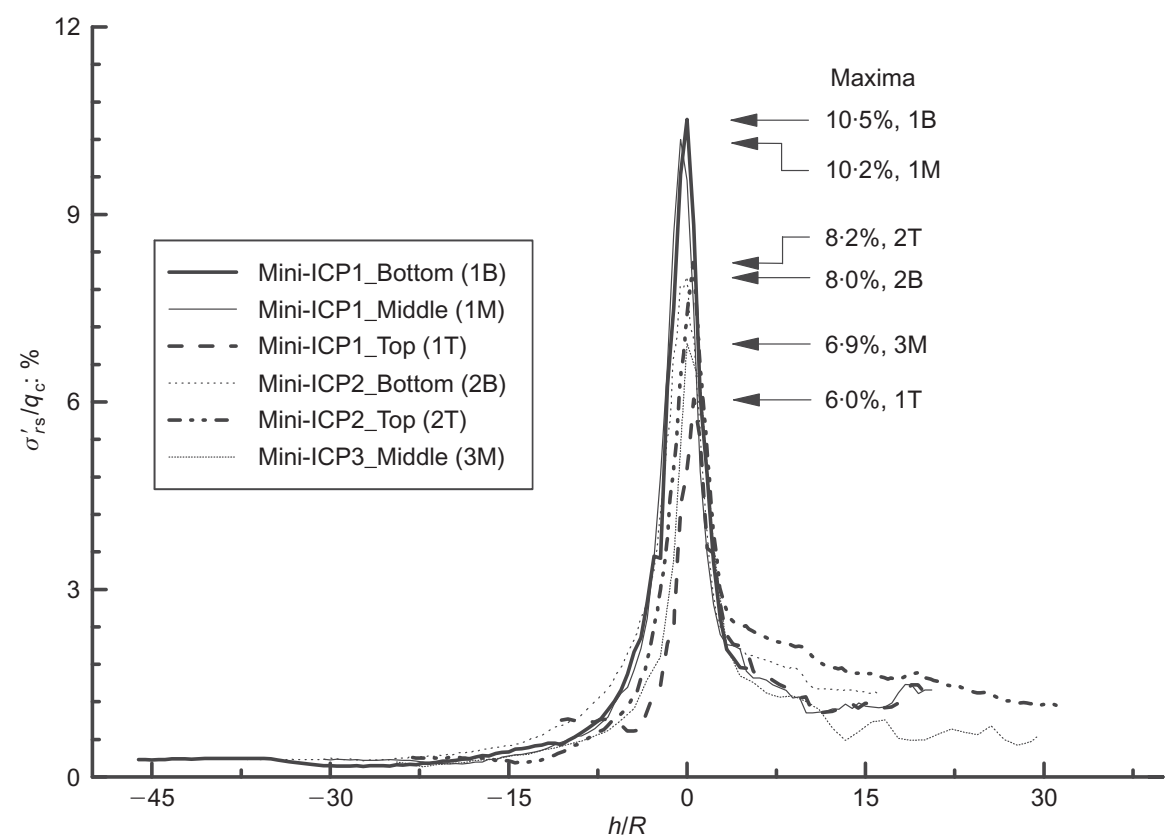

(b)

Fig. 4. Normalised radial stresses measured at $r / R=2$, also showing individual maximum values: (a) 'moving' and (b) 'stationary' traces from three tests plotted against relative pile tip depth, $h / R$

and $-0 \cdot 80$ respectively) imply gradients that are substantially flatter than measured gradients.

Figure 7 presents the individual stationary radial stresses measured at levels above the pile tip $(h / R>5)$ after the final stroke of (a) CPT2 and (b) the three Mini-ICP tests, covering $6<h / R<41$. The 'stationary' soil sensor measurements, made well above the tip, are more scattered than the 'moving' maxima discussed above. The measurements made on the pile shaft (at $r / R=1$ ) were, however, made with the much larger, stiffer, and more accurate Mini-ICP instruments. Interpreted profiles have been plotted for four $h / R$ values, with the on-pile measurements made at $r / R=1$ providing critically important evidence of marked near-shaft stress reductions. An iterative process was required to interpret the final stationary stress conditions applying in the region above the pile tip after installation, by consider- ing in parallel: the interrelated $\sigma_{\theta \mathrm{s}}^{\prime}$ and $\sigma_{z \mathrm{~s}}^{\prime}$ trends (following the equilibrium approach detailed in Appendix 2); upper-bound stationary stress maxima taken from the contour plots at the $h / R=0.5$ level; and the need to limit the implied $K_{\mathrm{P}}$ and $\phi^{\prime}$ values, accounting for the vertical shear stresses applied by the shaft. The interpreted stresses do not tend to far-field $K_{0}$ conditions over the soil volume considered. Rimoy (2012) has confirmed that pile installation leads to significant radial stress perturbations out to $r / R=33$ in calibration chambers having rigid boundaries. However, his tests, which include an active system that gives a better simulation of in situ far-field conditions (following Huang \& Hsu, 2004) indicate that $\sigma_{r \mathrm{~s}}^{\prime} / q_{\mathrm{c}}$ is not unduly sensitive to the boundary arrangements over the $r / R$, $h / R$ range considered.

The interpreted $\sigma_{r \text { s }}^{\prime}$ trends are compatible with the impor- 


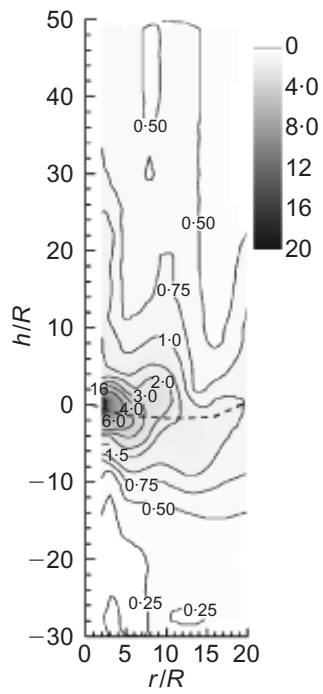

(a)
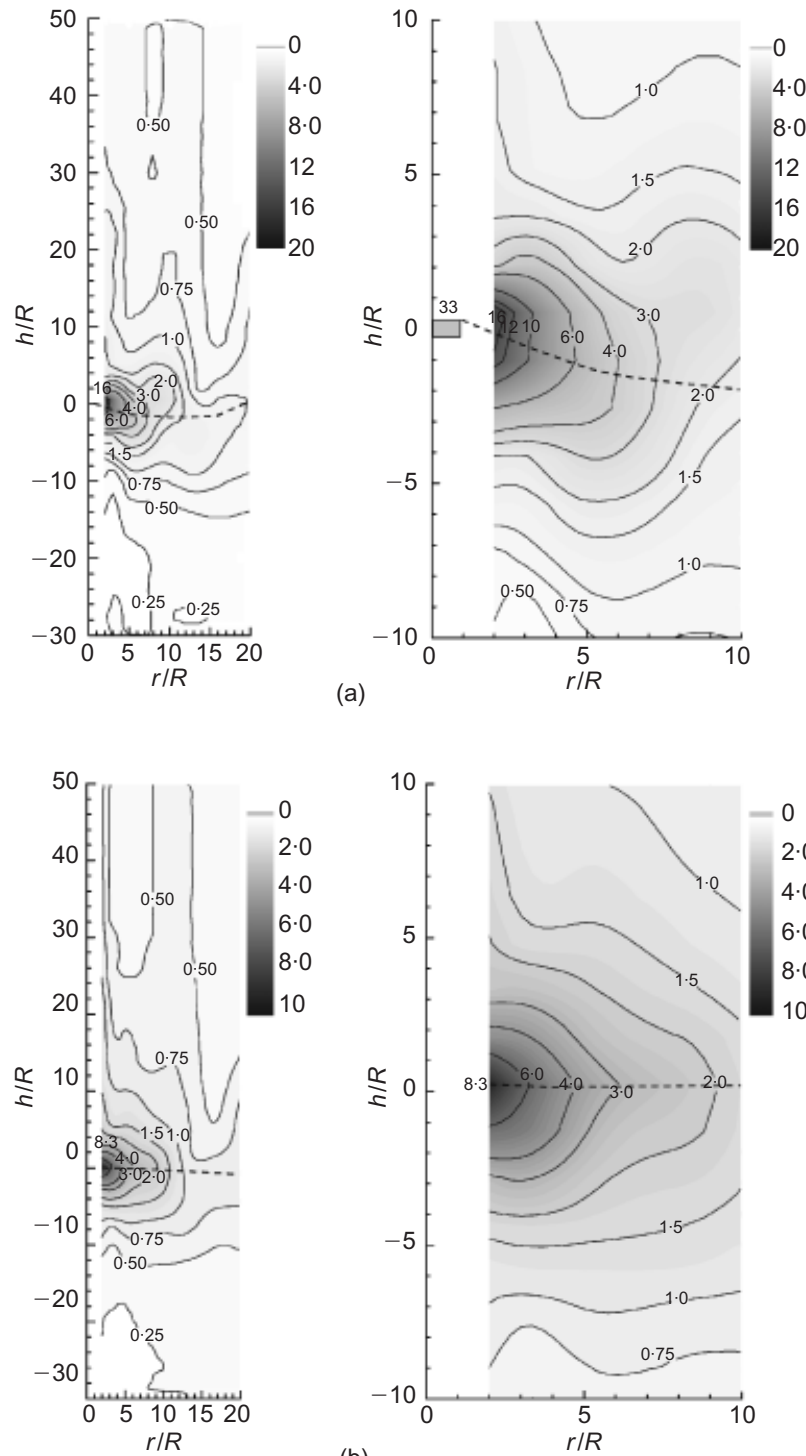

(b)

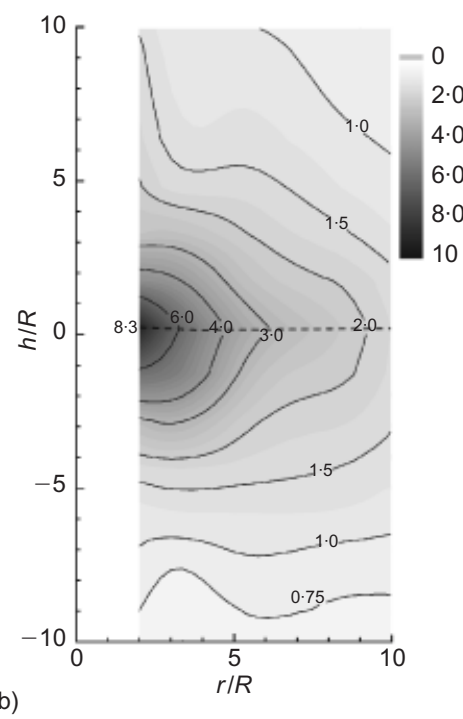

Fig. 5. Radial stress contours during installation shown at two scales, normalised by $q_{\mathrm{c}}$, shown in \%: (a) 'moving' conditions at end of each push $\left(\sigma_{r \mathrm{~m}}^{\prime}\right)$; (b) 'stationary' at end of each pause $\left(\sigma_{r \mathrm{~s}}^{\prime}\right)$. Dashed curves show locus connecting maxima developed in each case

tant dependence of local shaft friction capacity on $h / R$ observed in field tests by Lehane et al. (1993) and Chow (1997). The profiles show maxima at $r / R \approx 3$ that are around double those measured on the shaft at $r / R=1$ and decline systematically with $h / R$ at all $r / R$ ratios. Yang et al. (2010) linked these features with (a) strain path reversals that take place as the soil flows past the shoulder of the pile tip (which reduce the stresses dramatically and lead to arching with $\sigma_{\theta}^{\prime}>\sigma_{r}^{\prime}$ near the shaft), and (b) the development of an annulus of intensely compressed, fractured and sheared sand around the shaft, whose thickness grew from around $0.5 \mathrm{~mm}$ to a maximum of $1.8 \mathrm{~mm}$ as the tip advanced to its final depth. Load cycling and compression within this band were interpreted as the principal causes of the shaft radial stresses falling with increasing $h / R$. Potential scale effects are implied, as the interface shear bandwidths are controlled initially by grain size alone (Frost et al., 2004; Ho et al., 2011), and grow with absolute shear displacement rather than pile diameter (Yang et al., 2010; Ho et al., 2011). Steeper normalised stress gradients $\delta \sigma_{r}^{\prime} / \delta(r / R)$ and $\delta \sigma_{\theta}^{\prime} / \delta(r / R)$ could apply to full-scale piles, potentially affect-
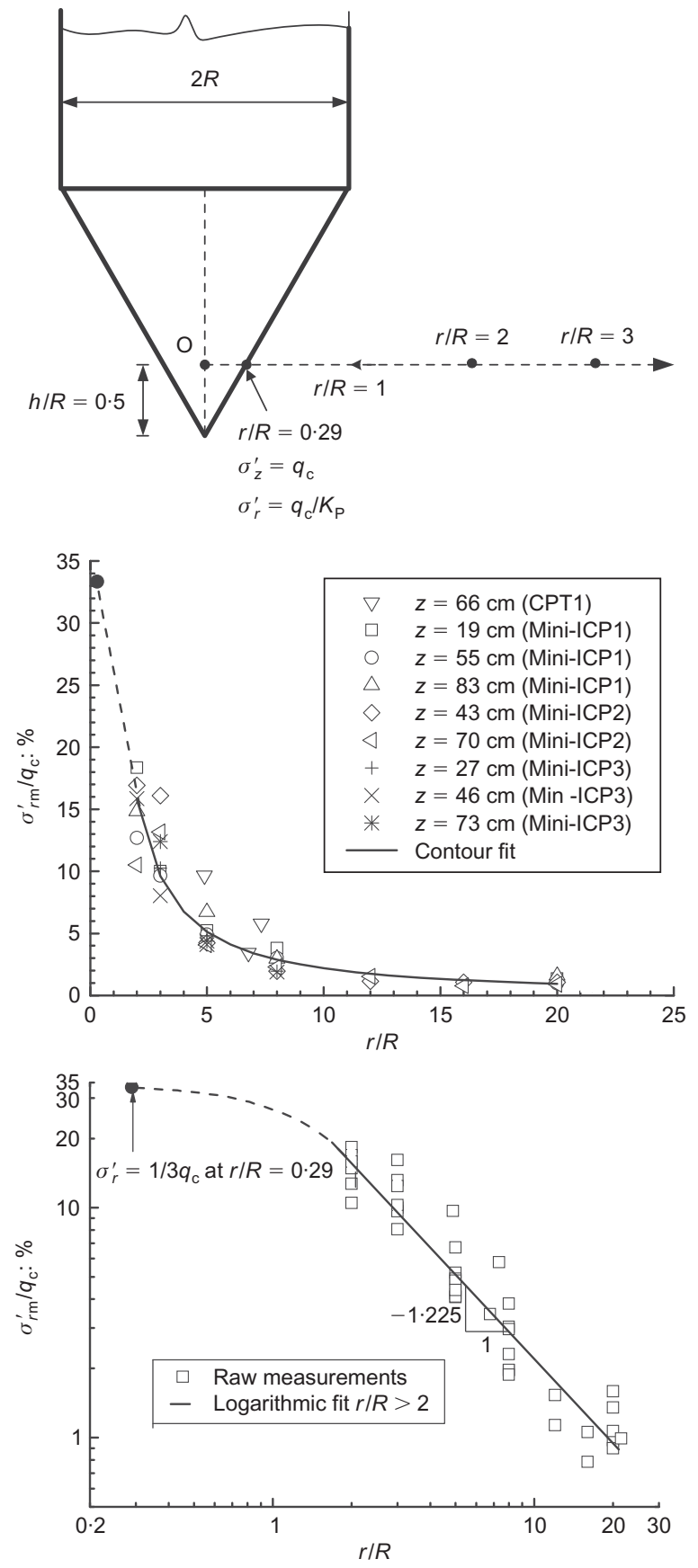

Fig. 6. Non-dimensional 'moving' radial stresses developed at $h / R=0.5$ during penetration

ing processes such as the time dependence reported by Jardine et al. (2006).

\section{Circumferential stress}

Unlike radial stresses, direct measurements could not be made of $\sigma_{\theta \mathrm{s}}^{\prime}$ on the Mini-ICP shaft (at $r / R=1$ ). They are also very difficult to make in the near-field $1<r / R<3$ region. The radially oriented, disc-shaped sensors' finite sizes lead to $r / R$ varying by $\sim 0.4$ over their measurement surface; the near-field gauges also experience steep radial and vertical soil movement gradients that tend to part the connecting wires from the instrument bodies. Concerns also arise regarding the sensors' presence potentially affecting the near-field stresses and leading to under-registration of $\sigma_{\theta}^{\prime}$. These limitations led to fewer circumferential (than radial) gauges being installed, and a relatively high proportion of 


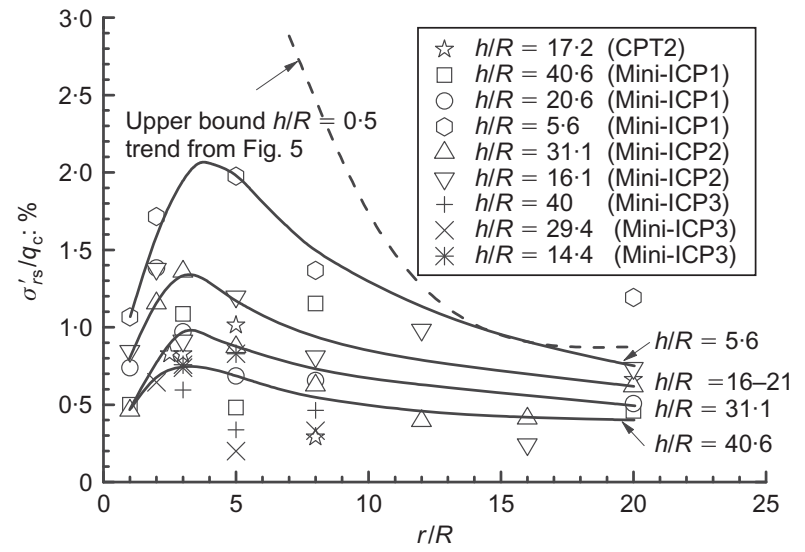

Fig. 7. Stationary radial stresses acting above pile tip $(h / R>5)$ after final jack stroke of installation, showing measurements and interpreted trends, with $h / R=0.5$ trend shown dashed from Fig. 5

those placed at low $r / R$ ratios failing as the pile tips passed by their particular level. The $\sigma_{\theta}^{\prime}$ datasets are relatively sparse, and have comparatively high COVs. The contour plots in Fig. 8 summarise the $\sigma_{\theta}^{\prime}$ measurements made, again highlighting sharp stress concentrations at $h / R=0.5$ and the significant jacking cyclic spans. While stresses and cyclic
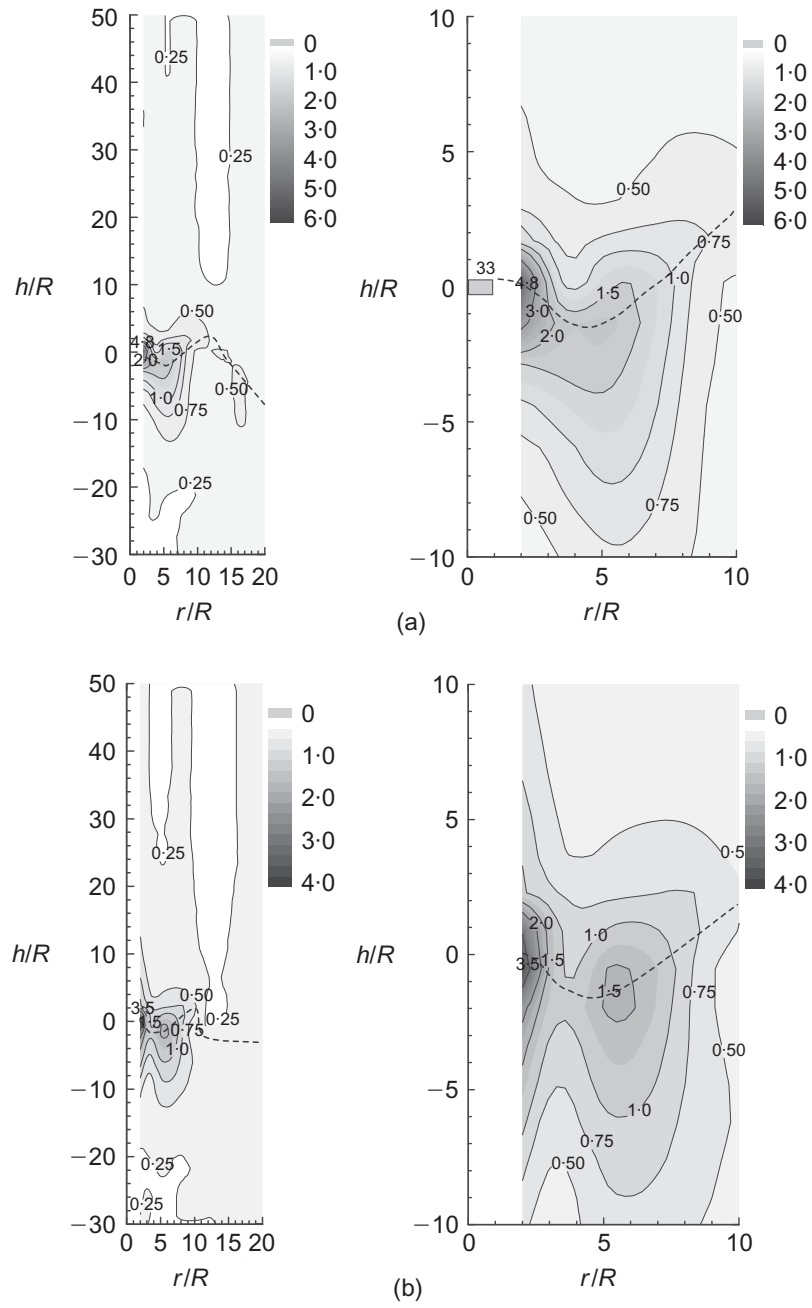

Fig. 8. Circumferential stress contours during installation at two scales, normalised by $q_{\mathrm{c}}$, shown in \%: (a) 'moving' conditions at end of each push $\left(\sigma_{\theta \mathrm{m}}^{\prime}\right)$; (b) 'stationary' at end of each pause ( $\left.\sigma_{\theta \mathrm{s}}^{\prime}\right)$. Dashed curves show locus connecting maxima developed in each case amplitudes are generally smaller than in the equivalent $\sigma_{r}^{\prime}$ plots, axial symmetry gives $\sigma_{\theta}^{\prime}=\sigma_{r}^{\prime}$ under the centreline, leading again to a $\sigma_{\theta \mathrm{m}}^{\prime}$ maximum of $K_{\mathrm{A}} q_{\mathrm{c}}=q_{\mathrm{c}} / 3$ during steady penetration. The scattered $\sigma_{\theta \mathrm{m}}^{\prime}$ profiles presented in Fig. 9 for $h / R=0.5$ indicate an exponent $c$ around -1.1 for $r / R>2$ that is similar to that for $\sigma_{r \mathrm{~m}}^{\prime}$, and projects up to the expected cone surface estimate of $q_{\mathrm{c}} / 3$.

Figure 10 presents stationary $\sigma_{\theta \mathrm{s}}^{\prime}$ measurements made

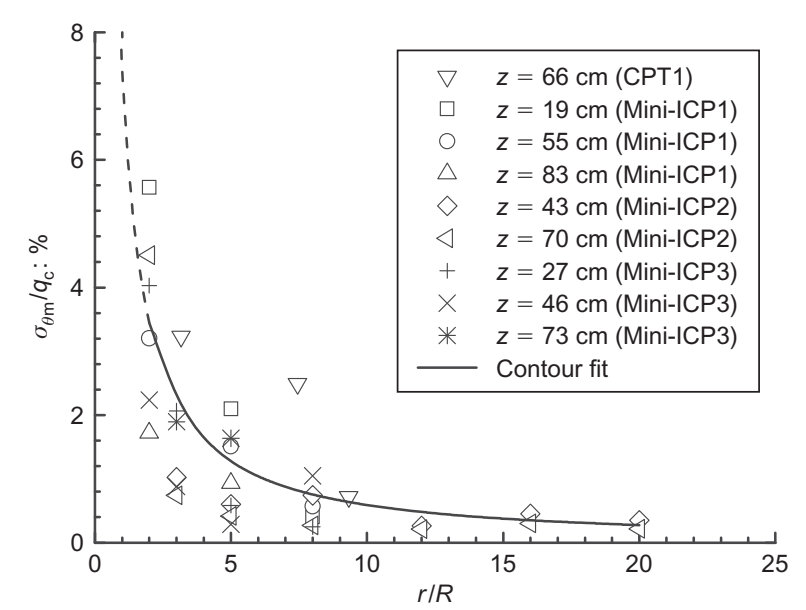

(a)

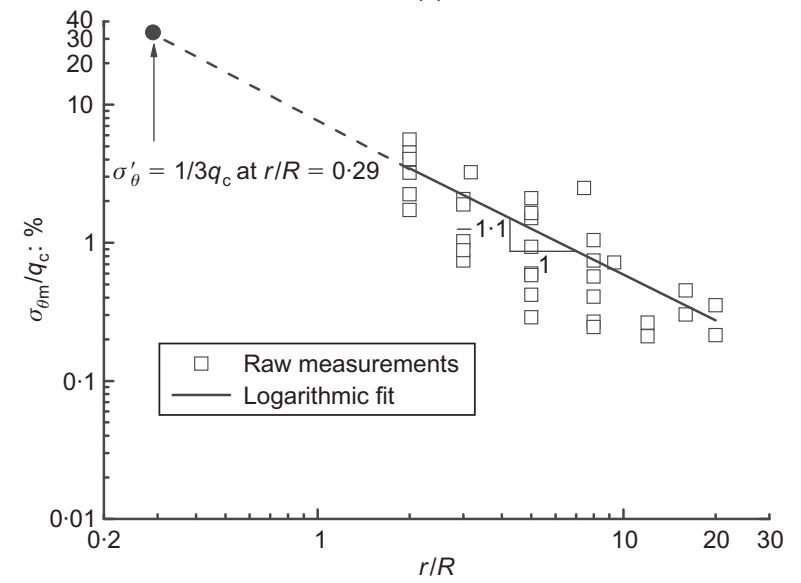

(b)

Fig. 9. Non-dimensional 'moving' circumferential stresses developed at $h / R=0.5$ during penetration

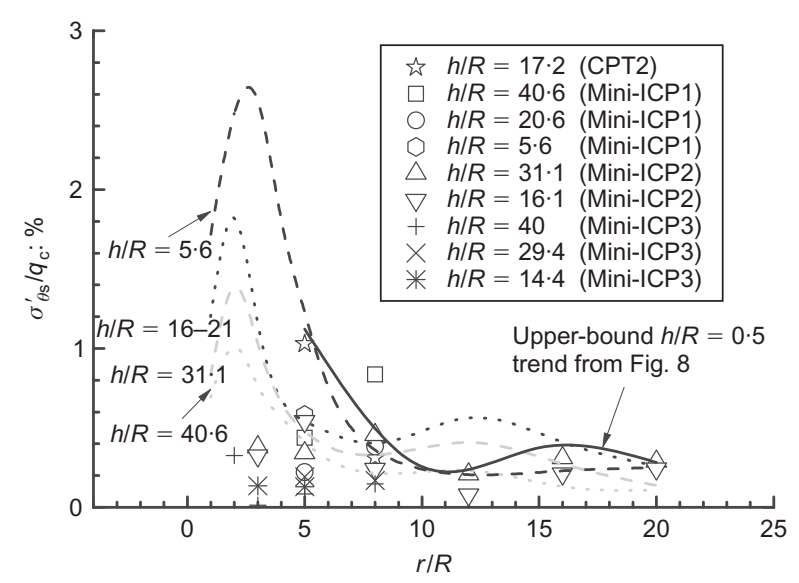

Fig. 10. Stationary circumferential stress measurements after final jack stroke of installation. Dashed curves show interpreted profiles projected applying simplified equilibrium equations to radial stress profiles given in Fig. 7 , with $h / R=0.5$ trend shown solid from Fig. 8 
above the tip after the final jack stroke. As explained above, there are very few data for $r / R<5$. The degree of scatter, which increases with $h / R$, makes it hard to establish clear trends, and the measurements made at low $r / R$ may not be reliable. Further insight into the near-field conditions can be gained from the more comprehensive and reliable radial stress dataset interpreted by considering the equilibrium relationships between $\sigma_{\theta \mathrm{s}}^{\prime}$ and $\sigma_{r \mathrm{~s}}^{\prime}$. As outlined in Appendix 2, $\sigma_{\theta}^{\prime}$ curves were derived (for points above the tip zone, with $h / R>5$ ) by applying the simplified cylindrical equilibrium equation (3) to the interpreted $\sigma_{r \mathrm{~s}}^{\prime}$ trends given in Fig. 7. The results are sensitive to the $\sigma_{r \mathrm{~s}}^{\prime} / q_{\mathrm{c}}-r / R$ distribution shapes, and iteration was required to produce an integrated interpretation of the combined experimental dataset.

$$
\sigma_{\theta}^{\prime}=\sigma_{r}^{\prime}+r \frac{\partial \sigma_{r}^{\prime}}{\partial r}
$$

The interpreted $\sigma_{\theta \text { s }}^{\prime}$ trends, shown as dashed curves in Fig. 10, were constructed by numerical differentiation and manipulation of the curves drawn in Fig. 7 through the scattered $\sigma_{r \text { s }}^{\prime}$ datasets. While their detailed shapes cannot be considered to be fully reliable, the assessment over the $1<r / R<3$ range of high $\sigma_{\theta \mathrm{s}}^{\prime} / q_{\mathrm{c}}$ ratios that exceed $\sigma_{r \mathrm{~s}}^{\prime} / q_{\mathrm{c}}$ is a secure and inescapable consequence of substituting into equation (3) the firm experimental evidence that $\partial \sigma_{r \mathrm{~s}}^{\prime} / \partial r$ is positive over this 'near-field' range. The projections are broadly comparable with the scattered measurements made at $5<r / R<20$, and the stationary $h /$ $R=0.5$ trend from Fig. 8, but pass above the sparser and potentially less reliable measurements made at $r / R=2$ and 3 .

\section{Vertical stresses}

The $\sigma_{z}^{\prime}$ measurements suffer from similar 'near-field' limitation to the $\sigma_{\theta}^{\prime}$ dataset. However, the contours presented in Fig. 11 show intense concentrations emanating from $r / R=0, h / R=0.5$ that are clearly non-symmetric about any horizontal plane. Stresses rise and fall sharply during each jacking cycle, with strong cyclic changes extending out to beyond $10 R$. The degree of pile-tip unloading during pauses depends on the ratio of shaft-to-base capacity, which varies with shaft length - particularly during the early stages of penetration. This is one factor that leads to higher COVs in the $\sigma_{z}^{\prime}$ measurements than for $\sigma_{\theta}^{\prime}$ or $\sigma_{r}^{\prime}$.

Very steep decays are shown with $r / R$ and $h / R$. It is hard to establish the vertical near-field stress trends, because, as with $\sigma_{\theta}^{\prime}$, there are no data for $r / R<2$. While $\sigma_{z \mathrm{~m}}^{\prime}$ must average around $q_{\mathrm{c}}$ within the zone just below the cone surface during penetration, the $\sigma_{z}^{\prime}$ maxima observed at the closest sensors $(r / R=2)$ amount to $0 \cdot 11 q_{\mathrm{c}}$, and fall to just $0 \cdot 02 q_{\mathrm{c}}$ before $h / R$ reaches 5 . The vertical stress maxima develop at the $h / R$ levels that trace out the falling locus with $r / R$ shown dashed in Fig. 11, and are two to three times higher than those at $h / R=0 \cdot 5$. The moving vertical stresses observed at $h / R=0.5$ are presented as radial profiles in Fig. 12, plotting all available data. The power law fit gives vertical stress decaying according to $(r / R)^{-1 \cdot 0}$ over the $2<r / R<20$ range.

Figure 13 summarises the final individual stationary vertical stresses measured at levels higher above the tip, along with the stationary trend curve applying at higher $r / R$ values at $h / R=0.5$ in Fig. 11. These show more scatter than the $\sigma_{r \mathrm{~s}}^{\prime}$ data; maxima of $0.8-1.4 \% q_{\mathrm{c}}$, and no clear variation with relative height above the tip (over $5.6<$ $h / R<40 \cdot 6$ ).
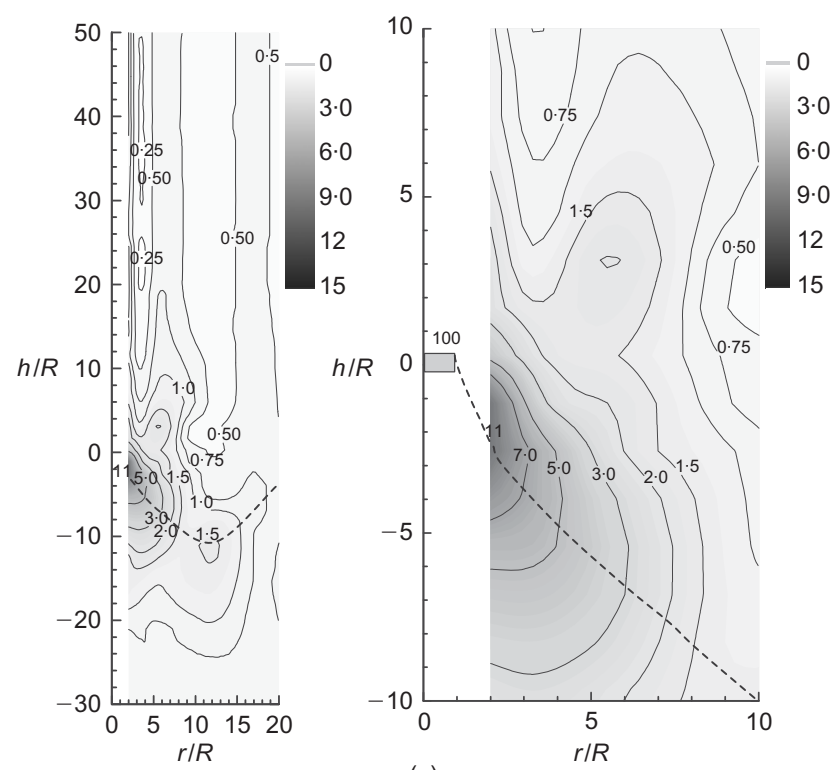

(a)
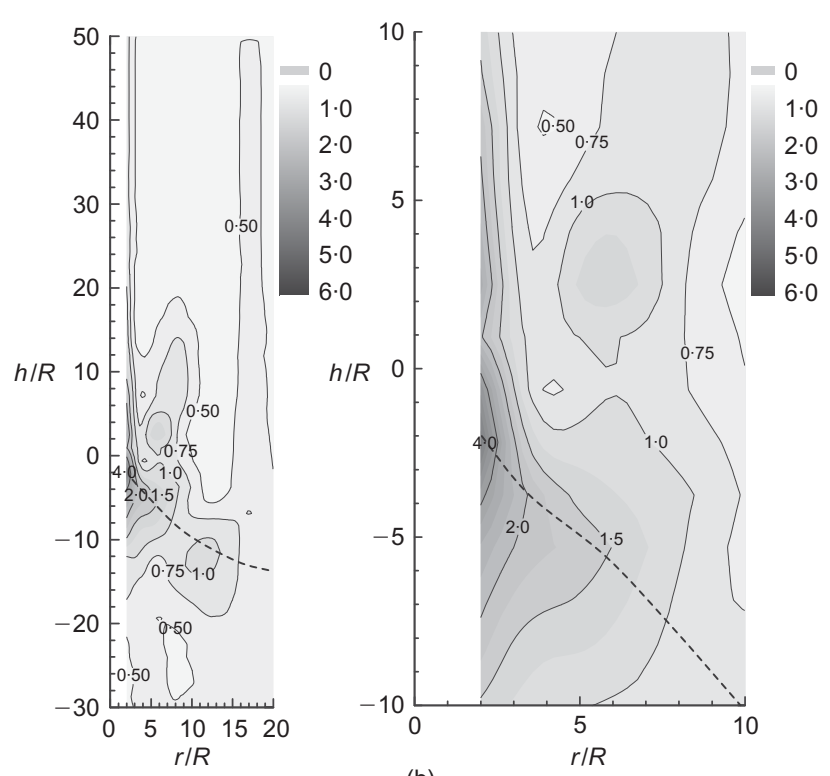

(b)

Fig. 11. Vertical stress contours during installation at two scales, normalised by $q_{\mathrm{c}}$, shown in \%: (a) 'moving' conditions at end of each push $\left(\sigma_{z m}^{\prime}\right)$; (b) 'stationary' at end of each pause $\left(\sigma_{z s}^{\prime}\right)$. Dashed curves show locus connecting maxima developed in each case

Applicability of cavity expansion theory to conditions close to the pile tip

The contour plots and radial profiles indicate that conditions are approximately hemispherically symmetrical, with a single stress concentration focused at $r / R=0, h / R \approx 0.5$, point $\mathrm{O}$ in Fig. 14. The presence of the pile body, and the contour patterns in Figs 5, 8 and 11, indicate that symmetry can hold only in the lower hemisphere of soil. In such a system, the profile of radial stresses acting on any line such as $\mathrm{A}-\mathrm{B}$ in Fig. 14 that was tangential to a circle of radius $a$ centred on $\mathrm{O}$ would match the vertical stress profile seen on an orthogonal line $\mathrm{C}-\mathrm{D}$. In the same way, the vertical stress profile on $\mathrm{A}-\mathrm{B}$ would match that for radial stress on $\mathrm{C}-\mathrm{D}$. This hypothesis can be tested against the least scattered moving stress measurements by noting that the vertical stress sensors provide near-continuous traces of $\sigma_{z}^{\prime}$ with $h / R$ (for points set at fixed $r / R$ positions), while the horizontal arrays of radial stress sensors provide (a sparser set of) individual 


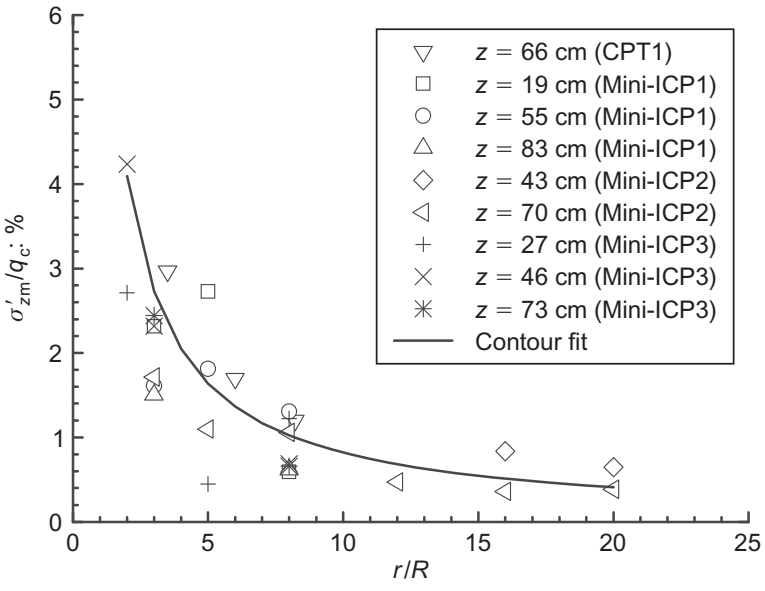

(a)

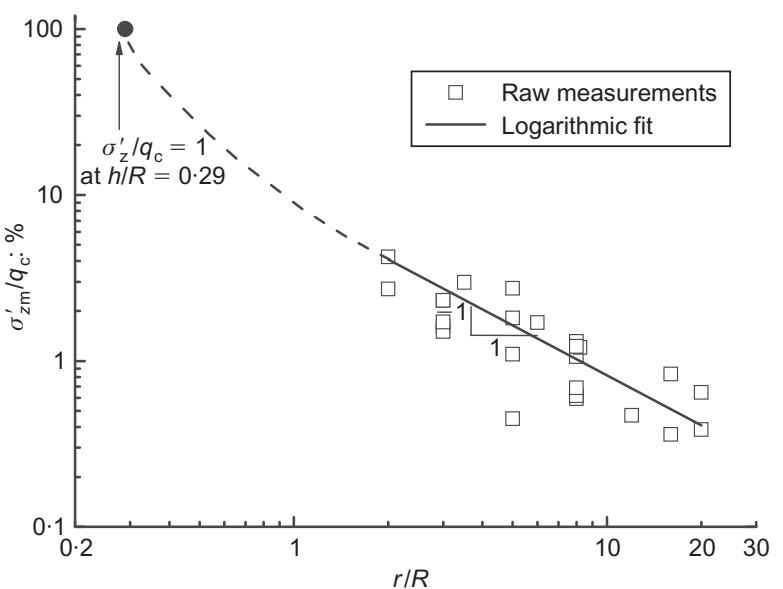

(b)

Fig. 12. Non-dimensional 'moving' vertical stresses developed at $h / R=0 \cdot 5$ during penetration

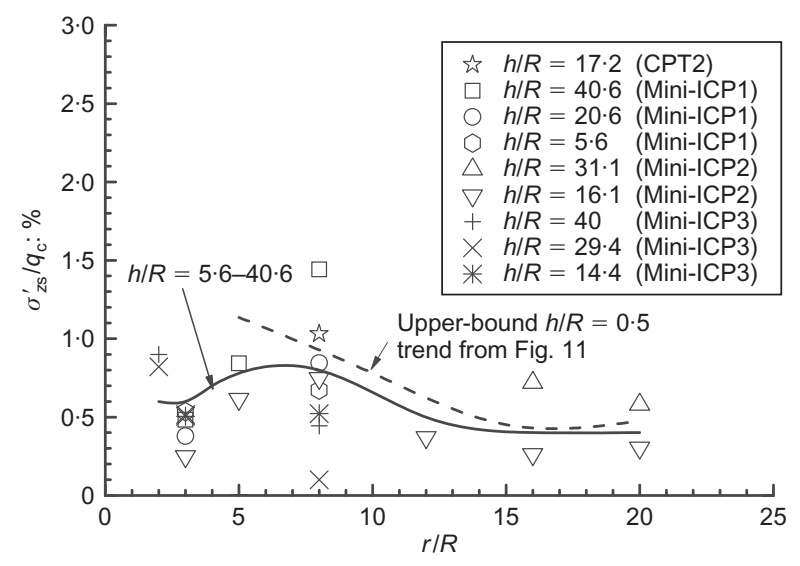

Fig. 13. Stationary vertical stresses acting at $h / R>5$ after final installation jack stroke, with $h / R=0.5$ trend shown dashed from Fig. 11

data points recorded at several $r / R$ values for a wide range of fixed $h / R$ values. The results are presented in Fig. 15, considering circles with radii $a / R=2,3,5$ and 8 respectively; $h^{\prime}$ is defined as the effective depth below point $\mathrm{O}$. While the orthogonal pairs of stress profiles show comparable maxima, the rates of stress decay $\delta \sigma_{r}^{\prime} / \delta r$ are noticeably steeper on horizontal lines $(\mathrm{C}-\mathrm{D})$ than the equivalent $\delta \sigma_{z}^{\prime} / \delta z$ gradients on vertical lines $(\mathrm{A}-\mathrm{B})$ for circles with $a / R$ up to 5 .

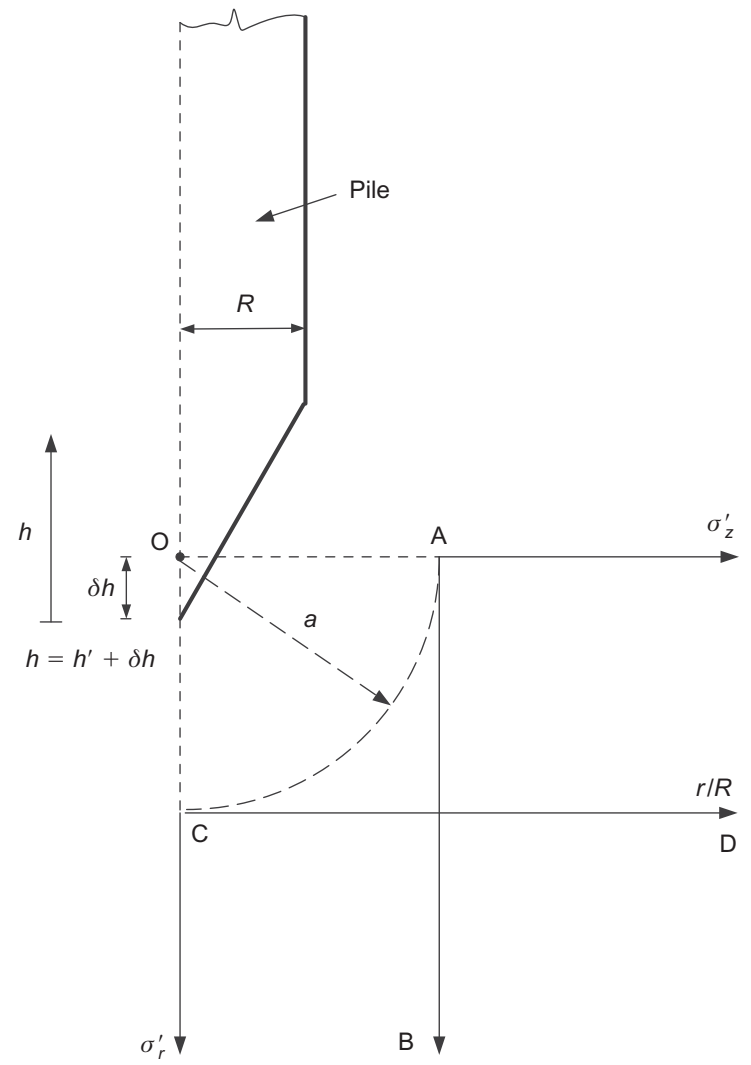

Fig. 14. Scheme of coordinates for investigating pile tip stress regime

Stress system acting over horizontal plane near tip $(h / R=0 \cdot 5)$

The assumption of spherical symmetry beneath point $\mathrm{O}$ permits further analysis of the trends interpreted for $\sigma_{r}^{\prime}, \sigma_{z}^{\prime}$ and $\sigma_{\theta}^{\prime}$ on the horizontal plane acting through $\mathrm{O}$. At this level, all three components are assumed to be principal stresses with $\sigma_{z}^{\prime}=\sigma_{\theta}^{\prime}, \sigma_{r}^{\prime}=\sigma_{1}^{\prime}$ and zero $\tau_{z r}$ or $\tau_{r z}$ shear stresses. Fig. 16(a) compares the power-law profiles taken from Figs 6, 9 and 12 relating $\sigma_{r \mathrm{~m}}^{\prime}, \sigma_{\theta \mathrm{m}}^{\prime}$ and $\sigma_{z \mathrm{~m}}^{\prime}$ values to $r / R$ (for $h / R=0.5$ ), and Fig. 16(b) presents the equivalent stationary stress plots. The largest near-field stresses are radial, and the circumferential and vertical stress trends intersect at $r / R \approx 1 \cdot 5$. The far-field stresses should tend towards $K_{0}$ conditions, but at $r / R$ ratios greater than those available with the INPG calibration chamber.

Radial profiles of $\sigma_{1}^{\prime} / \sigma_{3}^{\prime}$ and mobilised $\phi^{\prime}$ are plotted in Fig. 17 from the above. Conditions are not clear between $r / R=2$ and the tip, but the mobilised $\phi^{\prime}$ plots show dashed sections that assume $\sigma_{1}^{\prime} / \sigma_{3}^{\prime}=K_{\mathrm{P}}=3$ in the high-pressure, particle-crushing, tip zone. The penetration stage interpreted $\phi^{\prime}$ values rise to a maximum of $\sim 40^{\circ}$ at $r / R=2$, falling to $34^{\circ}$ at $r / R=15$. The trend with $r / R$ is interpreted as reflecting variations in

(a) the degree of unloading after pre-compression (at lower $h / R$ and $r / R$ ) of material swept aside by the tip as it passes the cone shoulder

(b) particle breakage

(c) sand compaction.

While stress ratios reduce during stationary periods (see Fig. 17(b)), the maximum mobilised $\phi^{\prime}$ calculated for pause stages remains about $40^{\circ}$ at $r / R=2$, falling marginally below the triaxial test maximum $42^{\circ}$. The results indicate that penetration induces a high degree of shear strength mobilisation that extends out to $r / R=15$ as the pile tip passes. 


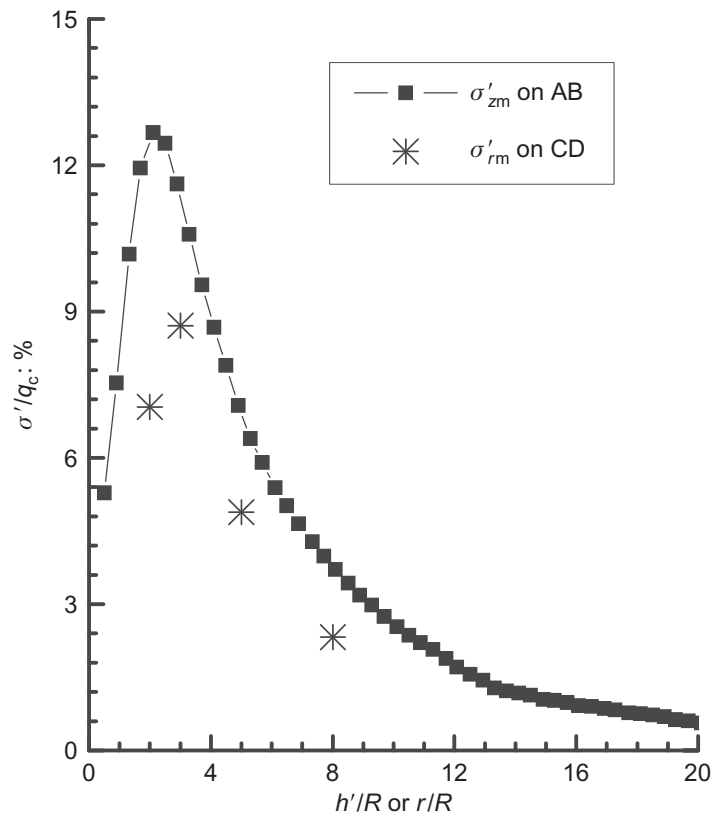

(a)

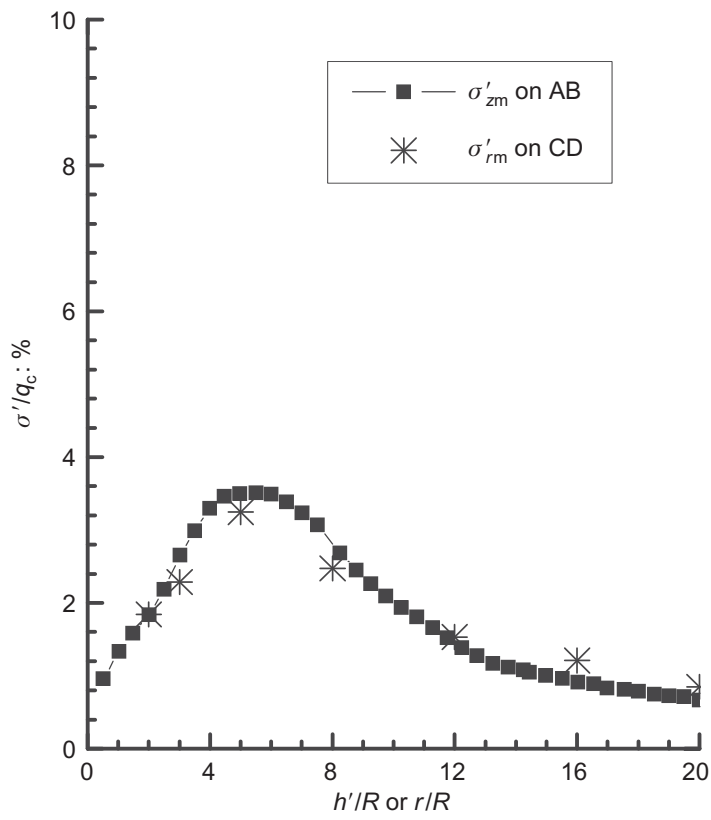

(c)

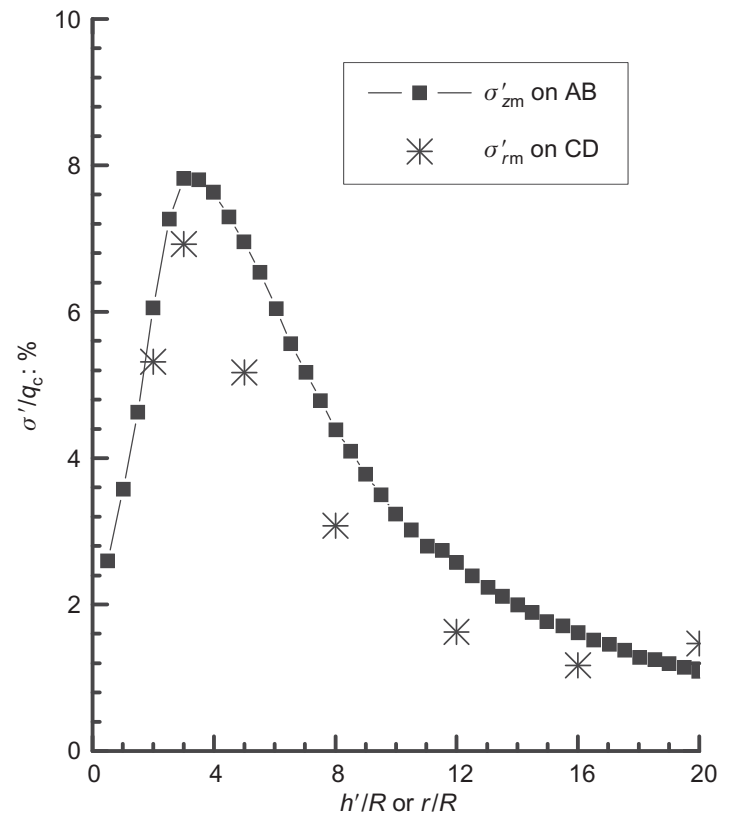

(b)

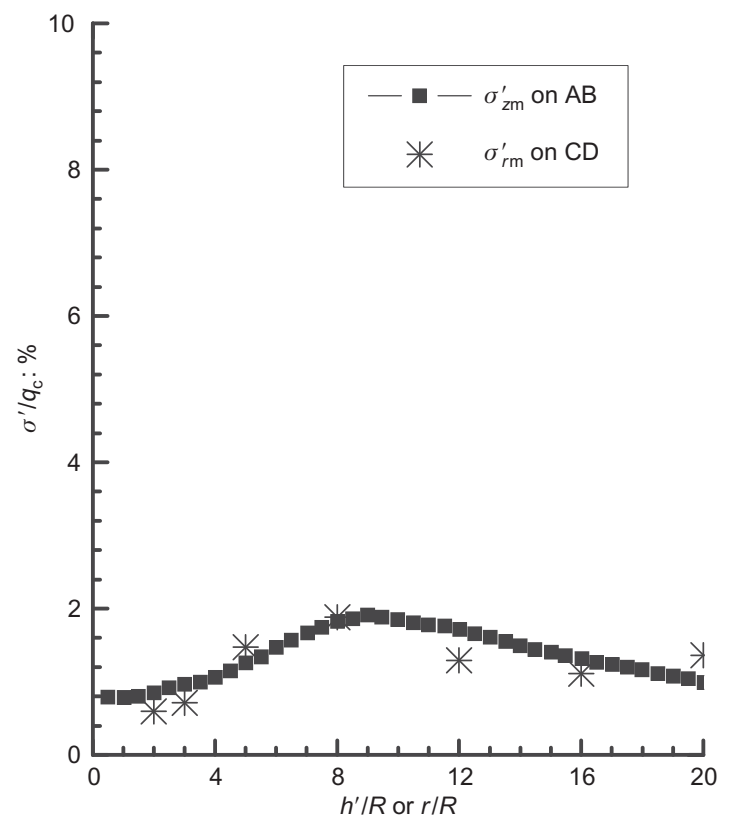

(d)

Fig. 15. Profiles of average 'moving' normal stresses from Mini-ICP tests on: (a) $A-B(r / R=2)$ and $C-D(h / R=-1 \cdot 5$ or $\left.h^{\prime} / R=2\right)$, radius $a=2 R ;(\mathrm{b}) \mathrm{A}-\mathrm{B}(r / R=3)$ and $\mathrm{C}-\mathrm{D}\left(h / R=-2 \cdot 5\right.$ or $\left.h^{\prime} / R=3\right)$, radius $a=3 R ;(\mathrm{c}) \mathrm{A}-\mathrm{B}(r / R=5)$ and $\mathrm{C}-\mathrm{D}$ $\left(h / R=-4 \cdot 5\right.$ or $\left.h^{\prime} / R=5\right)$, radius $a=5 R ;(\mathrm{d}) \mathrm{A}-\mathrm{B}(r / R=8)$ and $\mathrm{C}-\mathrm{D}\left(h / R=-7 \cdot 5\right.$ or $\left.h^{\prime} / R=8\right)$, radius $a=8 R$

Radial variation of final stationary stresses in region above the pile tip

The large volume of stationary stress measurements are synthesised into the interpreted radial (normalised) profiles of $\sigma_{r}^{\prime}, \sigma_{z}^{\prime}$ and $\sigma_{\theta}^{\prime}$ given in Fig. 18 for $h / R$ values between 5.6 and $40 \cdot 6$; the residual vertical shear stress $\left(\tau_{r z}\right)$ distributions assessed from the Mini-ICP load cells calculated as set out in Appendix 2 are also shown. These trends show $\sigma_{\theta}^{\prime}>\sigma_{r}^{\prime}>\sigma_{z}^{\prime}$ out to $r / R \approx 3$ and steep gradients with respect to $r / R$ that generally lead to $\sigma_{r}^{\prime}>\sigma_{z}^{\prime}>\sigma_{\theta}^{\prime}$ but with $\sigma_{z}^{\prime}$ becoming more important at higher $r / R$. The stress regime would be expected to gradually trend to $K_{0}$ conditions at perhaps $r / R=100$ in the field, or in model experiments involving a much larger diameter calibration chamber (Huang \& Hsu, 2004).

The results are clearly incompatible with any analogy based on monotonic cavity expansion. However, White et al. (2005) developed an interesting cylindrical cavity 'expansion-contraction' analysis, which is presented in Fig. 19. Here $\sigma_{r \max }^{\prime}$ represents the maximum radial stress imposed during an 'expansion' phase of the analysis, followed by inward radial contraction. The latter is designed to give the order of shaft radial stress reduction expected at an $h / R$ comparable to the friction sleeve of a standard CPT probe, with a mid-depth $h / R \approx 5 \cdot 7$. White et al.'s analysis shows stress maxima developing some distance from the shaft, as well as $\sigma_{\theta \mathrm{s}}^{\prime}>\sigma_{r \mathrm{~s}}^{\prime}$ for $r / R<4$. The present authors compare the predictions with the experimental trends by: (a) scaling the analysis, assuming from above that $\sigma_{r \max }^{\prime}=q_{\mathrm{c}} K_{\mathrm{A}}=q_{\mathrm{c}} / 3$; and (b) adding the final stationary data trend from Fig. 18 for $h / R=5 \cdot 6$. The measured $\sigma_{r \mathrm{~s}}^{\prime} / \sigma_{r \max }^{\prime}$ and $\sigma_{\theta \mathrm{s}}^{\prime} / \sigma_{r \max }^{\prime}$ ratios fall far below the predic- 


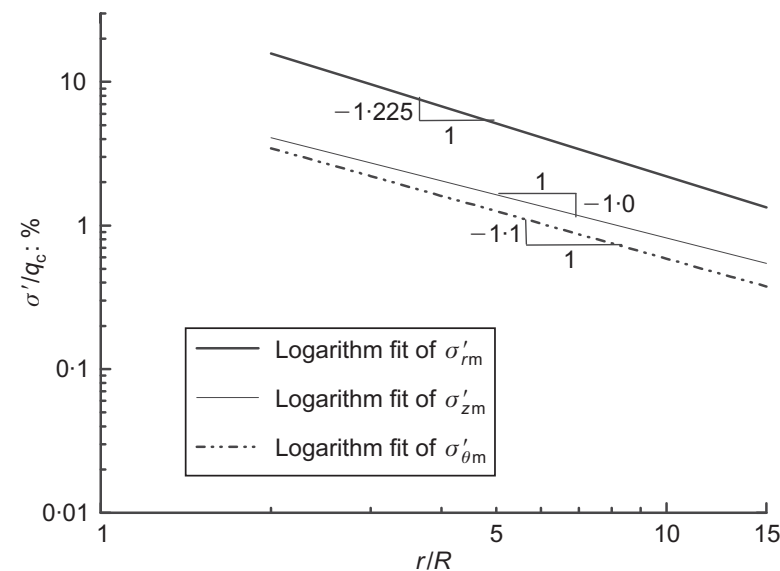

(a)

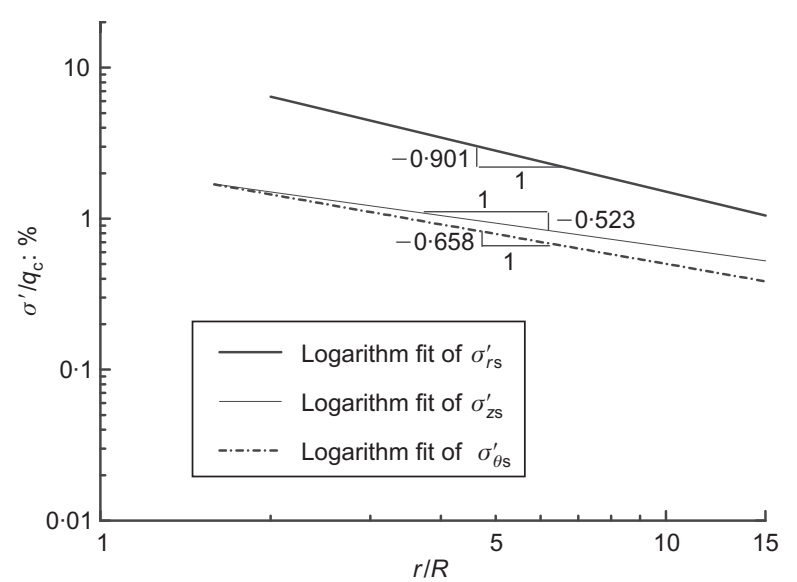

(b)

Fig. 16. Hierarchy of orthogonal stress components at $h / R=0 \cdot 5$ during (a) 'moving' and (b) 'stationary' stages

tions at most points away from the pile shaft. More complex aspects of the stress-strain histories need to be addressed to capture the experimental finding. Recent advanced numerical analyses by Henke et al. (2010) and Qiu et al. (2011) indicate potentially promising improvements in modelling this challenging problem.

Significant vertical shear stresses $\tau_{r z}$ also act adjacent to the shaft during jacking stages and pauses. The simplified equilibrium equations given in Appendix 2 indicate $\tau_{r z}$ distributions that diminish inversely with radius from the shaft that can be evaluated from the Mini-ICP measurements by applying equation (4).

$$
\tau_{r z}=\left[\tau_{r z}\right]_{r=R} R / r
$$

When non-zero vertical shear stresses act on the shaft, $\sigma_{r}^{\prime}$ and $\sigma_{z}^{\prime}$ can no longer be principal stresses, but must always fall between $\sigma_{1}^{\prime}$ and $\sigma_{3}^{\prime}$. However, $\sigma_{\theta}^{\prime}$ must remain a principal stress to keep axial symmetry. Combining the normal stress and $\tau_{r z}$ trends allowed $\sigma_{1}^{\prime}$ and $\sigma_{3}^{\prime}$ to be evaluated and checks made of the variations with $r / R$ of mobilised $\phi^{\prime}$ and $K_{\mathrm{P}}$. The degree of shear strength mobilisation is generally high; the $\phi^{\prime}$ values approach the laboratory maximum of $42^{\circ}$ over significant volumes of soil.

\section{SUMMARY AND CONCLUSIONS}

Establishing the stress conditions around displacement piles installed in sand is critical to improving the understanding and modelling of features such as non-linear load-displacement behaviour, group installation effects, and capacity variations with time. Stresses measured on, and

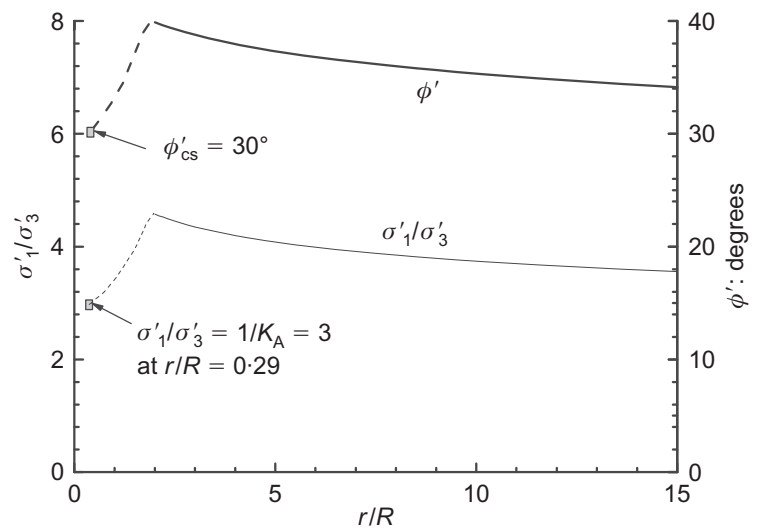

(a)

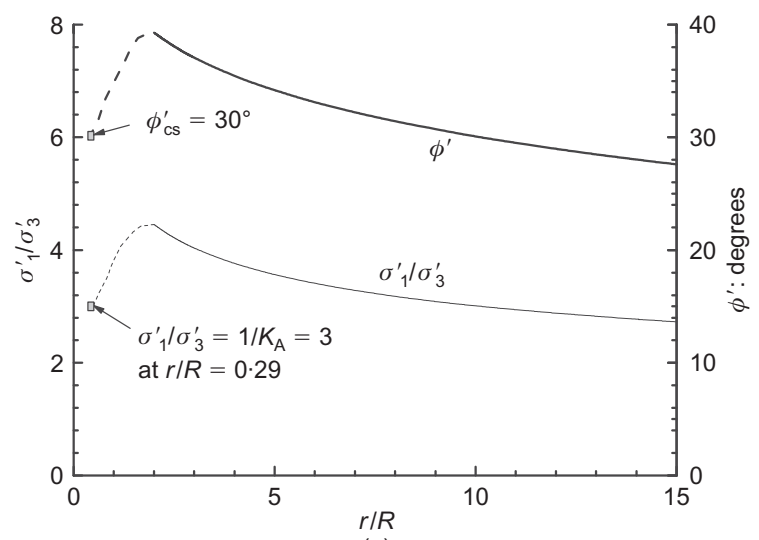

(a)

Fig. 17. Stress ratios and mobilised angles of shearing resistance $\phi$ ' at $h / R=0.5$ during (a) 'moving' and (b) 'stationary' stages of installation

around, a closed-ended model displacement pile jacked into medium-dense fine sand have allowed the radial, circumferential and vertical stress distributions to be described by (a) simplified axisymmetric contour maps and (b) profiles of individual stress components plotted for selected tip and shaft locations. The measurements were particularly difficult to make, and individual stress data points are shown to be liable to substantial scatter. The interpretation procedure addressed these difficulties by: very careful (non-linear) stress-cell calibrations; taking large numbers of measurements; data synchronisation; normalisation by locally measured CPT $q_{\mathrm{c}}$ values; averaging and non-dimensional contouring; and an integrated approach that considered both equilibrium considerations and the failure criteria from parallel laboratory tests. New insights are provided by the experiments into the fundamental processes affecting displacement pile installation in sand, allowing alternative hypotheses to be tested. The main conclusions are as follows.

(a) The stresses developed at any point depend principally on the local CPT tip resistance and the spatial position relative to the pile tip $(r / R$ and $h / R)$, as expressed by the form given in equation (1).

(b) The number of jacking cycles had little influence on the soil mass stresses, and no strong time effects were evident. However, these parameters may be more important at the pile/soil interface, during dynamic installation and over extended periods of time. Further investigation is under way by Rimoy (2012).

(c) Contour maps that capture the measured installation stresses in the form expressed by equation (1) have been developed to provide consistent descriptions of (i) the progressive stress build-up experienced at any given 


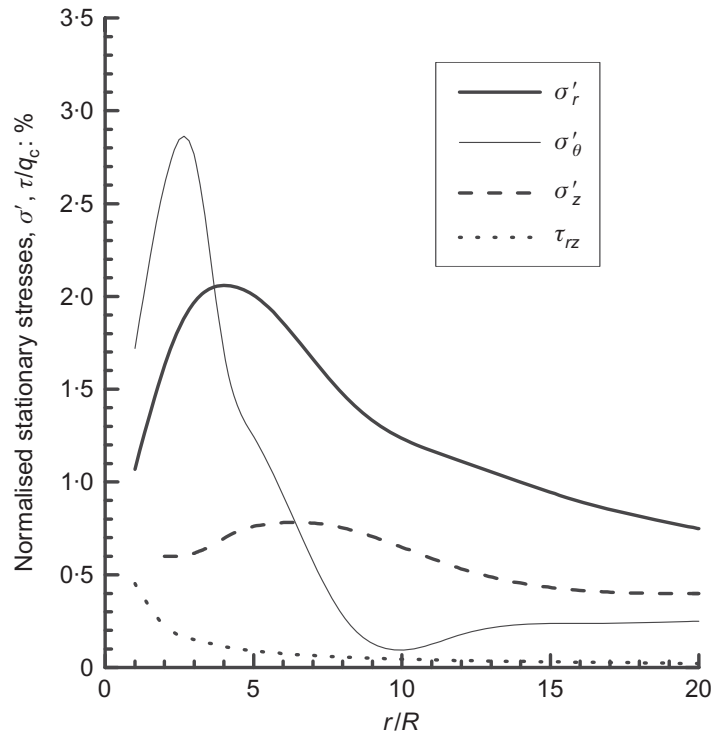

(a)

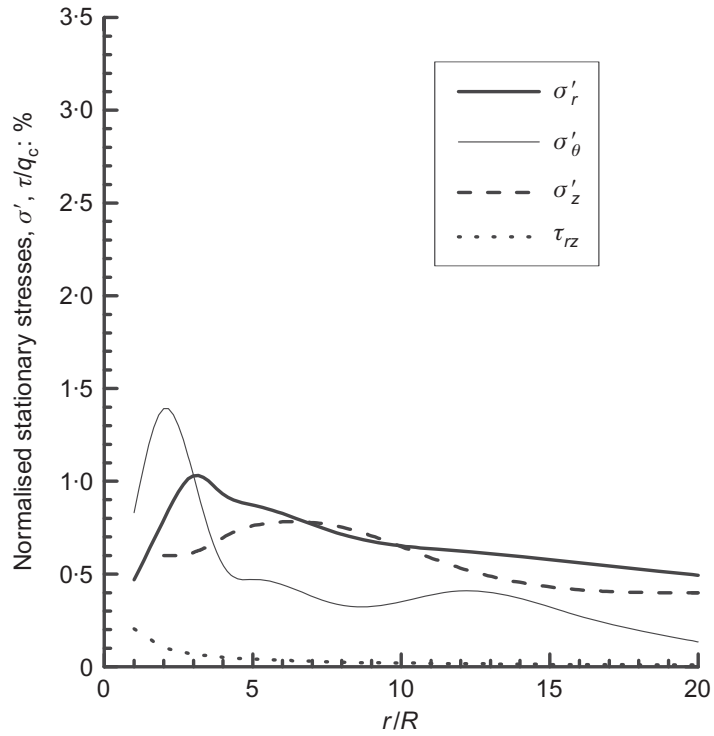

(c)

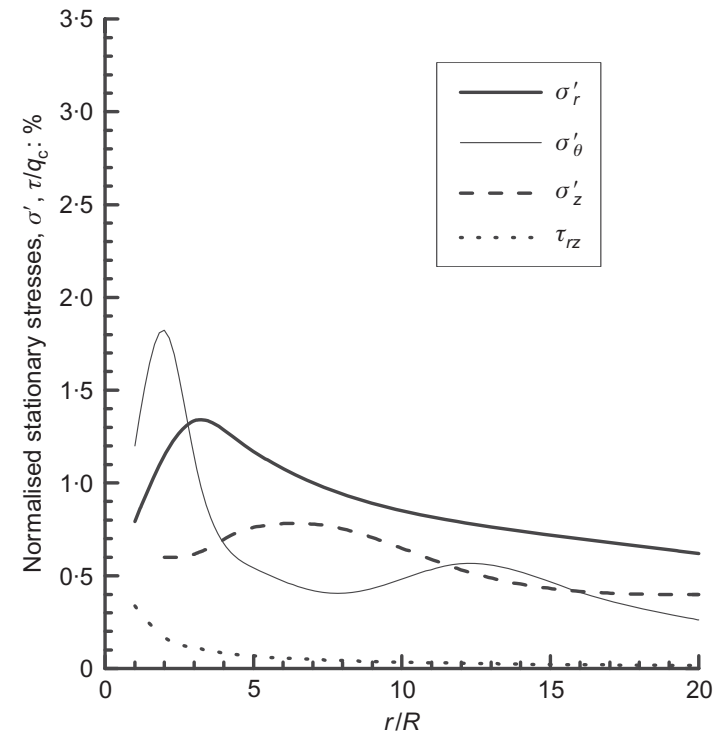

(b)

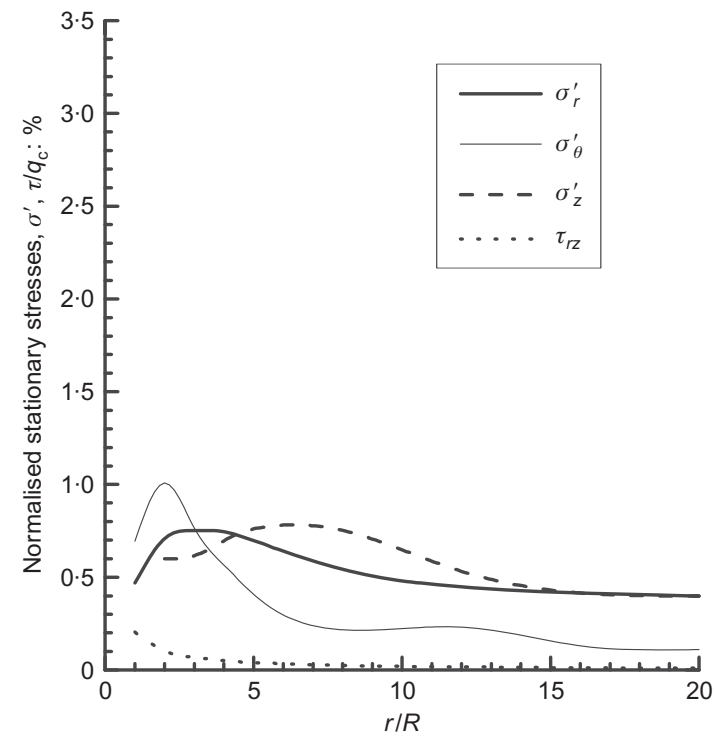

(d)

Fig. 18. Summary of interpreted normalised stationary stresses at: (a) $h / R=5 \cdot 6$; (b) $h / R=16-21$; (c) $h / R=31 \cdot 1$; (d) $h / R=40 \cdot 6$

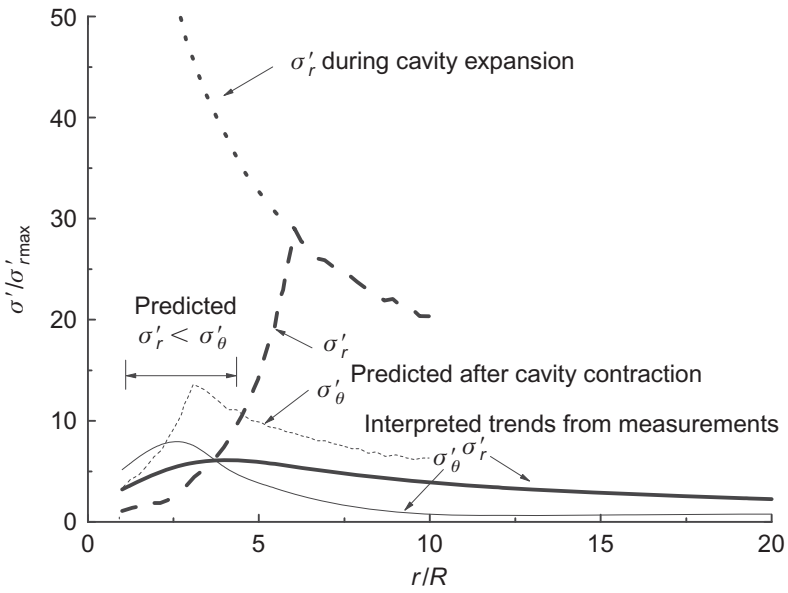

Fig. 19. Comparison of 'stationary' stress distributions around shaft at $h / R=5.6$ with illustrative cavity expansion-contraction model of White et al. (2005) depth below ground as the pile tip approaches and (ii) the sharp reductions that follow as the tip advances past this depth.

(d) The maps show intense stress concentrations emanating from the tip, at $r / R=0, h / R=0 \cdot 5$. Sand positioned within ten radii of this moving focus experiences a relatively high-level stress cycle during each installation jack stroke.

(e) Stress distributions established in the soil below and to either side of the 'tip-level' stress focus are approximately spherically symmetrical during both moving (penetration) and pause stages, although there are slight deviations between the stress decay curves established on vertically and horizontally projected distributions.

( $f$ ) Radial profiles of moving stresses plotted for the $h / R=0.5$ level show, for points with $r / R>2$, $\sigma_{r \mathrm{~m}}^{\prime}=\sigma_{1}^{\prime}$ and approximately power-law decay relationships with $r / R$, as predicted by constant- $\phi^{\prime}$ spherical cavity expansion analyses (Yu \& Houlsby, 1991). Minor deviations were noted that may be due to geometrical 
idealisation, mobilised $\phi^{\prime}$ variations, or differences in stress level, degree of unloading, particle breakage and compaction.

(g) Very steep stress gradients apply close to the pile tip, with triaxial compression dominating immediately beneath the tip, where $\sigma_{z}^{\prime}=\sigma_{1}^{\prime} \approx q_{\mathrm{c}}$ and $\sigma_{r \mathrm{~m}}^{\prime}=\sigma_{\theta \mathrm{m}}^{\prime}=q_{\mathrm{c}} / K_{\mathrm{P}}$.

(h) The stress distributions interpreted for $r / R>2$ at $h / R=0.5$ imply high mobilised $\phi^{\prime}$ values around the pile tip, even under zero pile-head loads. The highest interpreted $\phi^{\prime}$ is close to the maxima developed in triaxial tests that matched the local stress and strain history.

(i) The radial stress regime applying after installation displays maxima at normalised significant radial distances of around $r / R=3$ that are about double those acting on the shaft $(r / R=1)$. The radial stresses all decay with radius at $r / R>3$, and, for any given $r / R, \sigma_{r \mathrm{~m}}^{\prime} / q_{\mathrm{c}}$ falls systematically with $h / R$.

( $j$ ) Consideration of the radial equations of equilibrium indicates that circumferential stresses must also vary steeply over the $1<r / R<5$ range. Analysis indicates that $\sigma_{r \mathrm{~s}}^{\prime}<\sigma_{\theta \mathrm{m}}^{\prime}$ over $1<r / R<3$ after installation, although practical limitations made this feature impossible to observe directly.

(k) The observation of radial stress maxima at some radial distance from the shaft is in qualitative agreement with illustrative cylindrical cavity expansion-contraction analyses by White et al. (2005). However, the measured stress magnitudes fall considerably below their analytical estimates. Additional aspects of the installation process need to be considered, as in recent numerical analyses by Henke et al. (2010) and Qiu et al. (2011).

(l) Yang et al. (2010) interpret the dip in radial stresses developed above the tip at $r / R<3$ as being due to the strain paths developed around the pile tip, as well as the effects of cyclic loading, particle breakage, creep and stress relaxation. These processes persist as penetration continues, and are thought to contribute to the steady decline with $h / R$ of shaft $\sigma_{r \text { s }}^{\prime}$ seen in field and laboratory tests.

(m) Simplified analyses of the stationary stress regime applying around the pile shaft indicate distributions of mobilised $\phi^{\prime}$ that are plausible in comparison with laboratory test trends, showing a generally high degree of shear strength mobilisation.

\section{ACKNOWLEDGEMENTS}

The research described was funded by Shell UK Limited, the UK Health and Safety Executive, the UK Engineering Physical Sciences Research Council, Total France, and the UK Royal Society and the Natural Science Foundation of China (Nos. 51011130162 and 51178421). Their support is gratefully acknowledged. The authors acknowledge gratefully the contributions of Dr Mark Emerson, Dr Satoshi Nishimura, Dr Cristina Tsuha, Mr Jean-Benoit Toni, Mr Steve Ackerley, Mr Clive Dalton, Mr Siya Rimoy, Mr Bernard Rey, Mr Alan Bolsher, Mr Matias Silva and Mr Francesco La Malfa.

\section{APPENDIX 1: PROCEDURES FOR DATA REDUCTION AND PROCESSING}

As outlined in Tables 1-3, the CPT and three Mini-ICP tests employed multiple vertical, radial and circumferential sensors to measure $\sigma_{z}^{\prime}, \sigma_{r}^{\prime}$ and $\sigma_{\theta}^{\prime}$. The strategy for data reduction and processing involved using combined sets considering single stress components and fixed $r / R$ position. The number of representative 'moving peak' and 'stationary minima' interpreted from each soil stress cell varied between 50 and 200 per test, depending on the jack stroke lengths and measurement intervals employed for the installation. The spread of results obtained for each particular sensor type and position was relatively broad (see Figs 3 and 4).

A series of steps was taken to reduce the scatter and improve the clarity of the evidence available for interpretation. First, all soil stress measurements were normalised by the local $q_{\mathrm{c}}$ values to allow for any differences in sand mass placement, surcharge level or test boundary conditions. Second, the records available from all instruments were grouped according to their particular $r / R$, and synchronised to ensure that they conformed to common origins with respect to pile tip position $h / R$. As shown schematically in Fig. 20, the specific steps taken were as follows.

1. Locate for each individual trace of $\sigma^{\prime} / q_{\mathrm{c}}$ the nominal $h / R$ value (termed $x_{i}$ here, and based on surveyed instrument placement depth) at which $\sigma^{\prime} / q_{\mathrm{c}}$ has its maximum.

2. Calculate for each stress component and $r / R$ value, the average $h / R$ at which the maxima occur $\left(=1 / n\left(x_{1}+x_{2}+\ldots+x_{n}\right)\right.$, where $n$ is the number of available curves of $\sigma^{\prime} / q_{\mathrm{c}}-h / R$ for the particular stress and the fixed $r / R$.

3. Translate each $\sigma^{\prime} / q_{\mathrm{c}}-h / R$ curve slightly so that its maximum $x_{i}$ coincides with the location of the average $h / R$. This process is designed to remove the effects of any possible errors related to mismeasurement of the relative depths between the pile tip and soil sensors, assuming that any errors are random rather than systematic.

4. Compute from the ensemble of synchronised $\sigma^{\prime} / q_{\mathrm{c}}$ traces an average curve, finding for set of $h / R$ intervals the mean normalised stress as $1 / n\left(y_{1}+y_{2}+\ldots+y_{n}\right)$, where $y_{1}-y_{n}$ are the $\sigma^{\prime} / q_{\mathrm{c}}$ values, and $n \geqslant 2$.

5. Noting that traces could start and end at different values of $h / R$, consideration was given to cases where only one trace is available, for example when considering large positive $h / R$ values, with all other traces having terminated at an earlier stage such as $x_{\text {break }}$, as shown in Fig. 20(b). Here the interpreted 'average' $\sigma^{\prime} / q_{\mathrm{c}}$ curve is extended by factoring the only available test data according to $\sigma^{\prime} / q_{\mathrm{c}}=y_{1}\left[y_{\text {average }} / y_{1}\right]_{x=1}$

6. Apply the above procedures to each family of sensors representing the same single stress component and fixed $r / R$ position to obtain a synchronised and averaged trace for each type and position.

The averaged and synchronised datasets (relating $\sigma^{\prime} / q_{\mathrm{c}}$ to $h / R$ for fixed $r / R$ ) were reduced to several hundred data points (see Tables 2 and 3 ) that were input into two-dimensional contouring routines that employed the gridding and interpolation algorithm of Renka \& Cline (1984). The latter is considered effective for datasets comprising 1000 or fewer irregularly scattered points. The routine partitions the set of irregular data points of $\sigma^{\prime} / q_{\mathrm{c}}=f(r / R, h / R)$ into 'triangles' that are as nearly equiangular as possible, and estimates the partial derivatives of the key values $\left(\sigma^{\prime} / q_{\mathrm{c}}\right)$ with respect to the spatial coordinates $(r / R$ and $h / R)$ of each point. It then computes from the measured $\sigma^{\prime} / q_{\mathrm{c}}$ and estimated partial derivatives values of $\sigma^{\prime} / q_{\mathrm{c}}$ at rectangular $(r / R, h / R)$ grid points having evenly spaced $r / R$ and $h / R$ values, as shown in Fig. 21. Interpolation of this three-dimensional surface leads to the contour plots illustrated in Figs 5, 8 and 11.

\section{APPENDIX 2}

In a cylindrical coordinate system, the equilibrium equations can be written as (with shear stress reciprocal principle applied)

$$
\begin{aligned}
& \frac{\partial \sigma_{r}^{\prime}}{\partial r}+\frac{1}{r} \frac{\partial \tau_{r \theta}}{\partial \theta}+\frac{\partial \tau_{r z}}{\partial z}+\frac{\sigma_{r}^{\prime}-\sigma_{\theta}^{\prime}}{r}=0 \\
& \frac{\partial \tau_{r \theta}}{\partial r}+\frac{1}{r} \frac{\partial \sigma_{\theta}^{\prime}}{\partial \theta}+\frac{\partial \tau_{\theta z}}{\partial z}+\frac{2 \tau_{r \theta}}{r}=0 \\
& \frac{\partial \tau_{r z}}{\partial r}+\frac{1}{r} \frac{\partial \tau_{\theta z}}{\partial \theta}+\frac{\partial \sigma_{z}^{\prime}}{\partial z}+\frac{\tau_{r z}}{r}=0
\end{aligned}
$$

Considering the symmetrical axially loaded pile with $\tau_{r \theta}=0$ and $\tau_{\theta z}=0$, the equations reduce to

$$
\begin{aligned}
& \frac{\partial \sigma_{r}^{\prime}}{\partial r}+\frac{\partial \tau_{r z}}{\partial z}+\frac{\sigma_{r}^{\prime}-\sigma_{\theta}^{\prime}}{r}=0 \\
& \frac{\partial \tau_{r z}}{\partial r}+\frac{\partial \sigma_{z}^{\prime}}{\partial z}+\frac{\tau_{r z}}{r}=0
\end{aligned}
$$




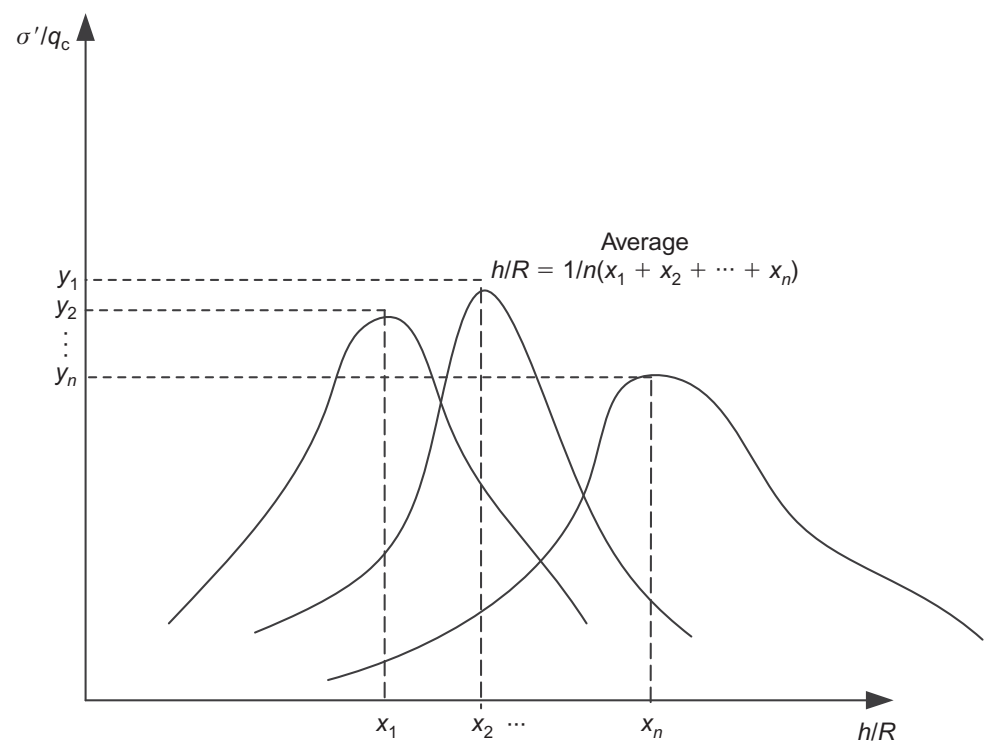

(a)

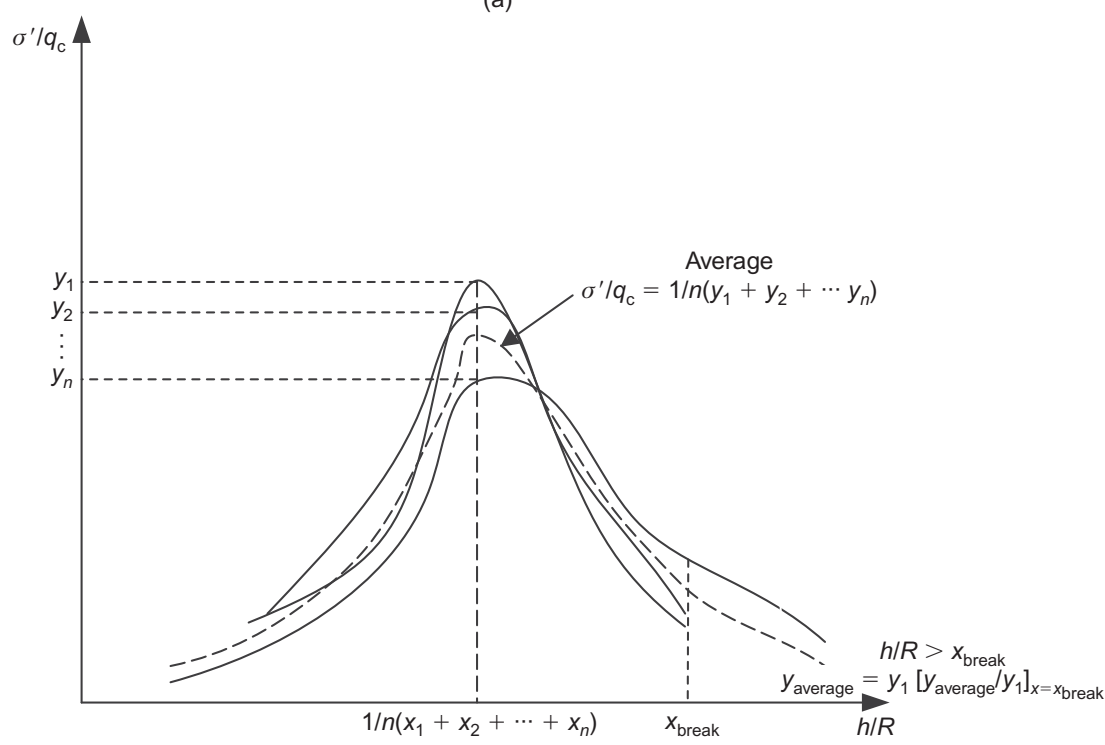

(b)

Fig. 20. Illustration of data reduction and processing scheme: (a) locating average $h / R$ for stress maximum; (b) synchronising curves to have their maxima as the same $h / R$, and extrapolating average curves to cope with data breaks

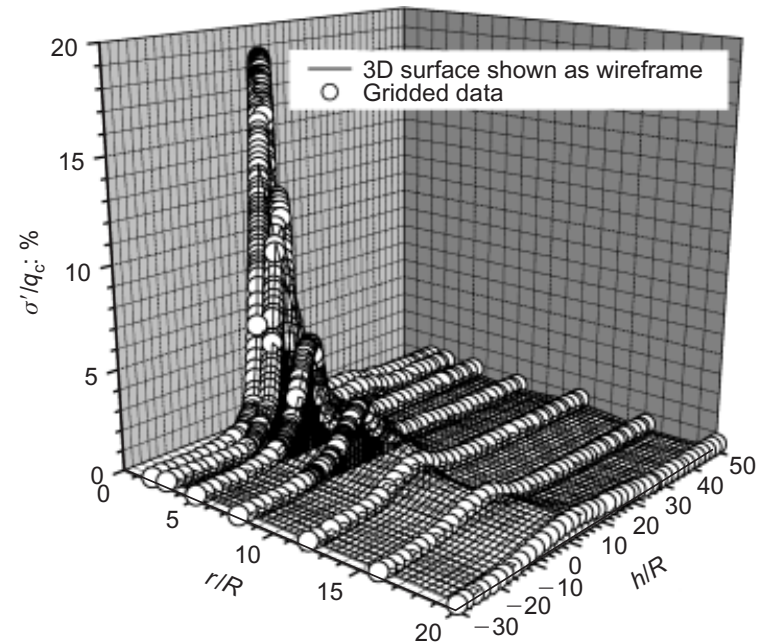

Fig. 21. Illustrative example of gridded data on 3D surface using Renka-Cline interpolation method for contouring, comprising combined averaged $\sigma_{r \mathrm{~m}}^{\prime}$ dataset from all tests
The observed gradients of shaft resistance with depth $\left[\partial \tau_{r z} / \partial z\right]_{r=R}$ are minor compared with the other terms in equation (8). If $\partial \tau_{r z} / \partial z$ is neglected then the commonly adopted approximation is obtained

$$
\frac{\partial \sigma_{r}^{\prime}}{\partial r}+\frac{\sigma_{r}^{\prime}-\sigma_{\theta}^{\prime}}{r}=0
$$

and at any point where the radial stress shows a maximum or minimum with respect to the radius with $\partial \sigma_{r}^{\prime} / \partial r=0, \sigma_{\theta}^{\prime}=\sigma_{r}^{\prime}$

Quantitative analysis of the plots presented in Figs 11 and 13 shows that the gradients $\partial \sigma_{z} / \partial z$ of the stationary stress can be neglected at levels above $h / R=5$. So it is possible to take

$$
\frac{\partial \tau_{r z}}{\partial r}=-\frac{\left[\tau_{r z}\right]_{r=R} R}{r^{2}}
$$

implying $\tau_{r z}=\left[\tau_{r z}\right]_{r=R} R / r$.

The above results are derived purely from consideration of static equilibrium, and apply independently of any feature of the soils' constitutive behaviour. 
NOTATION

$c, m, a$ coefficients for cavity expansion analysis and radius from cavity origin

$D_{50}$ particle diameter that corresponds to $50 \%$ point on particle size distribution

$D_{\mathrm{r}} \quad$ relative density of sand

$e_{0}$ initial void ratio

$h$ height above pile tip

$h^{\prime}$ effective depth below point $\mathrm{O}$ shown in Fig. 14

$K_{\mathrm{A}}, K_{\mathrm{P}} \quad$ Rankine coefficients of active and passive earth pressure

$L_{\mathrm{p}}$ penetration depth of pile tip

$N$ number of installation jacking stroke cycles

$p^{\prime}$ mean effective stress

$q_{\mathrm{c}} \quad$ CPT cone resistance

$R$ pile radius

$r$ radius of point from pile axis

$z$ depth below sand surface

$\delta^{\prime}$ effective angle of interface shearing resistance

$\sigma_{1}^{\prime}, \sigma_{2}^{\prime}, \sigma_{3}^{\prime}$ major, intermediate and minor principal effective stresses

$\sigma_{r}^{\prime}$ effective radial stress; $\sigma_{r \mathrm{~m}}^{\prime}, \sigma_{r \mathrm{~s}}^{\prime}, \sigma_{r \max }^{\prime}$ are moving, stationary and maximum values

$\sigma_{\theta}^{\prime}$ effective circumferential stress; $\sigma_{\theta \mathrm{m}}^{\prime}, \sigma_{\theta \mathrm{s}}^{\prime}, \sigma_{\theta \max }^{\prime}$ are moving, stationary and maximum values

$\sigma_{z}^{\prime}$ effective vertical stress; $\sigma_{z \mathrm{~m}}^{\prime}, \sigma_{z \mathrm{~s}}^{\prime}, \sigma_{z \max }^{\prime}$ are moving, stationary and maximum values

$\sigma_{z 0}^{\prime} \quad$ initial vertical stress

$\tau_{r z} \quad$ vertical shear stress on radial surface; $\tau_{z r}$ complementary shear stress

$\tau_{r \theta} \quad$ circumferential shear stress on radial surface; $\tau_{\theta r}$ complementary shear stress

$\tau_{\theta z} \quad$ vertical shear stress on circumferential surface; $\tau_{z \theta}$ complementary shear stress

$\phi^{\prime}$ effective angle of shearing resistance; $\phi_{\mathrm{cs}}^{\prime}$ critical state value

\section{REFERENCES}

Altuhafi, F. \& Jardine, R. J. (2011). Effect of particle breakage and strain path reversal on the properties of sands located near to driven piles. Proc. 5th Int. Symp. on Deformation Characteristics of Geomaterials, Seoul 1, 386-395.

Axelsson, G. (2000). Long-term set-up of driven piles in sand. $\mathrm{PhD}$ thesis, Department of Civil and Environmental Engineering, Royal Institute of Technology, Stockholm, Sweden.

Chow, F. C. (1997). Investigations into displacement pile behaviour for offshore foundations. PhD thesis, Department of Soil Mechanics, Imperial College, London, UK.

Chow, F. C., Jardine, R. J., Brucy, F. \& Nauroy, J. F. (1998). Effects of time on capacity of pipe piles in dense marine sand. J. Geotech. Geoenviron. Engng ASCE 124, No. 3, 254-264.

Frost, J. D., Hebeler, G. L., Evans, T. M. \& DeJong, J. T. (2004). Interface behaviour of granular soils. In Earth and space 2004 (eds R. B. Malla and A. Maji), pp. 65-72. Reston, VA, USA: ASCE.
Henke, S., Qiu, G. \& Grabe, J. (2010). A coupled Eulerian Lagrangian approach to solve geotechnical problems involving large deformations. Proc. 7th Eur. Conf. Numer. Methods Geotech. Engng, Trondheim, 233-238.

Huang, A. B. \& Hsu, H. H. (2004). Advanced calibration chambers for cone penetration testing in cohesionless soils. Proc. 2nd Int. Conf. Geotech. Geophys. Site Characterization, Porto, 147-166.

Jardine, R. J., Chow, F. C., Overy, R. F. \& Standing, J. R. (2005). ICP design methods for driven piles in sands and clays. London, UK: Thomas Telford.

Jardine, R. J., Standing, J. R. \& Chow, F. C. (2006). Some observations of the effects of time on the capacity of piles driven in sand. Géotechnique 56, No. 4, 227-244, http:// dx.doi.org/10.1680/geot.2006.56.4.227.

Jardine, R. J., Zhu, B. T., Foray, P. \& Dalton, J. C. P. (2009). Experimental arrangements for investigation of soil stresses developed around a displacement pile. Soils Found. 49, No. 5, 661-673.

Jardine, R. J., Zhu, B. T., Foray, P. \& Yang, Z. X. (2013). Measurement of stress field developed around close-ended piles in sand. Géotechnique 63, No. 1, 1-17, http://dx.doi.org/10.1680/ geot.9.P.137.

Ho, T. Y. K., Jardine, R. J. \& Minh, N. A. (2011). Large displacement interface shear between steel and granular media. Géotechnique 61, No. 3, 221-234, http://dx.doi.org/10.1680/geot.8.P.086.

Lehane, B. M., Jardine, R. J., Bond, A. J. \& Frank, R. (1993). Mechanisms of shaft friction in sand from instrumented pile tests. J. Geotech. Engng. Div. ASCE 119, No. 1, 19-35.

Qiu, G., Henke, S. \& Grabe, J. (2011). Application of a coupled Eulerian-Lagrangian approach on geomechanical problems involving large deformations. Comput. Geotech. 38, No. 1, 30-39.

Renka, R. J. \& Cline, A. K. (1984). A triangle-based C1 interpolation methods. Rocky Mountain J. Math. 14, No. 1, 223-237.

Rimoy, S. (2012). Internal technical report on calibration chamber experiments. London, UK: Imperial College.

Salgado, R., Mitchell, J. K. \& Jamiolkowski, M. (1997). Cavity expansion and penetration resistance in sand. J. Geotech. Geoenviron. Engng ASCE 123, No. 4, 344-354.

Vesic, A. S. (1972). Expansion of cavities in infinite soil mass. J. Soil Mech. Found. Div. ASCE 98, No. 3, 265-290.

White, D. J. \& Bolton, M. D. (2004). Displacement and strain paths during plane-plain model pile installation in sand. Géotechnique 54, No. 6, 375-397, http://dx.doi.org/10.1680/geot.2004.54. 6.375 .

White, D. J., Schneider, J. A. \& Lehane, B. M. (2005). The influence of effective area ratio on shaft friction of displacement piles in sand. Proc. 1st Int. Symp. on Frontiers in Offshore Geotechnics, Perth, 741-747.

Yang, Z. X., Jardine, R. J., Zhu, B. T., Foray, P. \& Tsuha, C. H. C. (2010). Sand grain crushing and interface shearing during displacement pile installation in sand. Géotechnique 60, No. 6, 469-482, http://dx.doi.org/10.1680/geot.2010.60.6.469.

Yu, H. S. \& Houlsby, G. T. (1991). Finite cavity expansion in dilatant soils: loading analysis. Géotechnique 41, No. 2, 173-183, http://dx.doi.org/10.1680/geot.1991.41.2.173. 